Transmission of Quantitative Easing: The Role of Central Bank Reserves Jens H.E. Christensen and Signe Krogstrup
SNB Working Papers
6/2015 


\section{Legal Issues}

\section{DISCLAIMER}

The views expressed in this paper are those of the author(s) and do not necessarily represent those of the Swiss National Bank. Working Papers describe research in progress. Their aim is to elicit comments and to further debate.

\section{COPYRIGHT@}

The Swiss National Bank (SNB) respects all third-party rights, in particular rights relating to works protected by copyright (information or data, wordings and depictions, to the extent that these are of an individual character).

SNB publications containing a reference to a copyright (C) Swiss National Bank/SNB, Zurich/year, or similar) may, under copyright law, only be used (reproduced, used via the internet, etc.) for non-commercial purposes and provided that the source is mentioned. Their use for commercial purposes is only permitted with the prior express consent of the SNB.

General information and data published without reference to a copyright may be used without mentioning the source. To the extent that the information and data clearly derive from outside sources, the users of such information and data are obliged to respect any existing copyrights and to obtain the right of use from the relevant outside source themselves.

\section{LIMITATION OF LIABILITY}

The SNB accepts no responsibility for any information it provides. Under no circumstances will it accept any liability for losses or damage which may result from the use of such information. This limitation of liability applies, in particular, to the topicality, accuracy, validity and availability of the information.

ISSN 1660-7716 (printed version)

ISSN 1660-7724 (online version)

(C) 2015 by Swiss National Bank, Börsenstrasse 15,

P.O. Box, $\mathrm{CH}-8022$ Zurich 


\title{
Transmission of Quantitative Easing: The Role of Central Bank Reserves
}

\author{
Jens H. E. Christensen \\ Federal Reserve Bank of San Francisco \\ jens.christensen@sf.frb.org \\ and \\ Signe Krogstrup \\ Swiss National Bank \\ signe.krogstrup@snb.ch
}

\begin{abstract}
We argue that the issuance of central bank reserves per se can matter for the effect of central bank large-scale asset purchases - commonly known as quantitative easingon long-term interest rates. This effect is independent of the assets purchased, and runs through a reserve-induced portfolio balance channel. For evidence we analyze the reaction of Swiss long-term government bond yields to announcements by the Swiss National Bank to expand central bank reserves without acquiring any long-lived securities. We find that declines in long-term yields following the announcements mainly reflected reduced term premiums suggestive of reserve-induced portfolio balance effects.
\end{abstract}

\section{JEL Classification: G12, E43, E52, E58}

Keywords: unconventional monetary policy, reserve-induced portfolio balance channel, term structure modeling

Previous versions of this paper have circulated under the title "Swiss Unconventional Monetary Policy: Lessons for the Transmission of Quantitative Easing." The paper has benefited immensely from discussions with Jürg Blum, Lucas Fuhrer, Massimo Giuliodori, Basil Guggenheim, John Kandrac, Thomas Kick, Sebastien Kraenzlin, Thomas Laubach, Mico Loretan, Christoph Meyer, Sarah Mouabbi, Jelena Stapf, Davide Tomio, Bernhard Winkler, and Anders Vredin. We thank participants at the First International Conference on Sovereign Bond Markets, the Third Joint Bank of Canada/Banco de España Workshop on "International Financial Markets," the BuBa-OeNB-SNB Workshop 2014, the SNB Annual Research Conference 2014, the DNB Annual Research Conference 2014, and the 18th Conference of the Swiss Society for Financial Market Research as well as seminar participants at the Federal Reserve Board and the Federal Reserve Bank of San Francisco for helpful comments. We also thank brown-bag seminar participants at the Swiss National Bank for helpful comments and suggestions on an early draft of the paper. Finally, we would like to thank Kevin Cook and Simon Riddell for excellent research assistance. The views in this paper are solely the responsibility of the authors and should not be interpreted as reflecting the views of the Federal Reserve Bank of San Francisco, the Board of Governors of the Federal Reserve System, or the Swiss National Bank.

This version: June 4, 2015. 


\section{Introduction}

A number of central banks have recently resorted to large-scale asset purchases - frequently referred to as quantitative easing (QE) - to provide further monetary stimulus with conventional policy rates constrained by the zero lower bound. The stated aims of such QE programs have differed across countries, but have usually involved reducing long-term interest rates, either broadly or in specific markets. While it is widely accepted that QE has helped reduce long-term interest rates (see, e.g., Gagnon et al. 2011 and Christensen and Rudebusch 2012 (henceforth $\mathrm{CR}$ )), the understanding of its transmission to long-term yields remains at best partial, theoretically as well as empirically, and has become the topic of a large and growing literature.

So far the literature has focused mainly on two channels of transmission. One is a signaling channel, which works through changing market expectations about future monetary policy (see, e.g., CR and Bauer and Rudebusch 2014); the other is a portfolio balance channel, which arises from the reduction in the available supply of the assets purchased. The lower supply may raise the prices of the purchased assets and of close substitutes (see, e.g., Gagnon et al. 2011 and Krishnamurthy and Vissing-Jorgensen 2011). ${ }^{1,2}$ Bernanke and Reinhart (2004), however, point out that portfolio balance effects of QE programs may arise through an additional reserve channel. ${ }^{3}$ Namely, the increase in the supply of bank reserves that accompanies asset purchases may put upward pressure on asset prices more broadly. To distinguish between these two portfolio balance channels, we refer to the former as a supply-induced portfolio balance channel and to the latter as a reserve-induced portfolio balance channel.

In this paper, we argue that QE programs can give rise to reserve-induced portfolio balance effects independently of the specific assets purchased. This phenomenon is due to a special feature of reserves, namely, that they can only be held by banks. Furthermore, using a stylized example, we demonstrate that the empirical relevance of reserve-induced portfolio balance effects depends crucially on how central bank asset purchases affect the balance sheets of banks and non-bank financial intermediaries.

To the best of our knowledge, there does not exist a theoretical model of the transmission of QE that takes these standard features of money markets into account. The seminal model of Vayanos and Vila (2009), which is the main reference in the literature used to provide the

\footnotetext{
${ }^{1}$ See also Joyce et al. (2011), Hamilton and Wu (2012), Thornton (2012), and Neely (2013) for discussions.

${ }^{2}$ There is another potential channel for QE to work, namely through its effect on liquidity and market functioning; see Christensen and Gillan (2014) and Kandrac (2014) for discussions and analysis in the context of US QE programs.

${ }^{3}$ Krogstrup et al. (2012) also make this point.
} 
theoretical foundation of portfolio balance effects, contains neither a central bank balance sheet nor central bank reserves. Instead, central bank asset purchases are modeled as an exogenous reduction in the available supply of the purchased assets. Moreover, the nature of banks' and non-banks' relationships with each other and the central bank is absent. ${ }^{4}$ Hence, the existing approach to modeling the transmission of QE to yields through portfolio balance effects cannot account for reserve-induced effects.

Similarly, the existing empirical literature on the effects of QE has not distinguished between supply- and reserve-induced portfolio balance effects. And for good reasons. When a central bank buys long-term securities through the creation of reserves, both types of portfolio balance effects would be at work and materialize simultaneously upon the announcement of such QE programs, thanks to the forward-looking behavior of bond investors. All three QE programs conducted by the Federal Reserve since 2008, and the Bank of England's asset purchase programs, were cases of simultaneous purchases of long-term bonds in exchange for newly issued reserves. ${ }^{5}$ The implication is that the portfolio balance effects on long-term yields documented in previous studies of QE programs may in fact reflect both supply- and reserve-induced portfolio balance effects.

In order to separately identify reserve-induced portfolio balance effects on long-term interest rates, we need a QE program that not only entails a substantial increase in the amount of central bank reserves but is achieved without acquiring any long-lived securities or close substitutes thereof. By design, such a program would be unlikely to give rise to any supplyinduced portfolio balance effects on long-term interest rates.

The unconventional monetary policies conducted by the Swiss National Bank (SNB) in August 2011 during the market upheavals of the European debt crisis included exactly such a program. To address increasing deflationary concerns and a rapid appreciation of the Swiss franc, the SNB announced three consecutive expansions of reserves - also known as sight deposits - held at the SNB. The expansions were achieved through purchases of short-term debt securities, repo operations, and short-maturity foreign exchange swaps. As such, the operations left the market supply of long-term Swiss franc bonds-as well as that of close

\footnotetext{
${ }^{4}$ Gertler and Karadi (2013) set up a model of QE in which financial market structure and financial balance sheets are explicitly included. The types of financial market features they consider are, however, very different from the ones we point out as potentially relevant in this paper.

${ }^{5}$ There is one exception, namely the Federal Reserve's Maturity Extension Program (MEP) that operated from September 2011 through 2012. This program involved purchases of more than $\$ 600$ billion of long-term Treasury securities (defined as bonds with more than six years to maturity) financed by selling an equal amount of shorter-term Treasuries (defined as bonds with less than three years to maturity). Thus, the MEP represents a case of sizable purchases and sales of securities without any change in the amount of reserves. See Cahill et al. (2013) and Li and Wei (2013) for analysis of the Fed's MEP.
} 
substitutes - unchanged. We use this program as a case study of the transmission of QE to long-term interest rates.

The question we are interested in is whether the SNB's expansion of reserves in August 2011 affected long-term Swiss government bond yields, and if so, through which channel(s). ${ }^{6}$ First, we document that yields did respond in the immediate aftermath of the announcements. Long-term Swiss Confederation bond yields dropped by a cumulative total of 28 basis points following the three SNB announcements of reserve injections. Relative to the yield on the ten-year Swiss Confederation bond of 1.33 percent on the eve of the first announcement, 28 basis points represent a substantial and highly significant drop. Given the short maturity of the assets that the SNB purchased, we argue that supply-induced effects of this particular program are likely to have been negligible. This leaves our proposed reserve-induced portfolio balance channel, tied to the increase in reserves held by banks as discussed above, and the signaling channel.

To separately identify the two latter channels in the data, we follow the literature and use dynamic term structure models combined with an event study approach similar to CR, who investigate the response of UK and US government bond yields to announcements regarding their respective unconventional monetary policy initiatives. Performing rolling daily re-estimations of dynamic term structure models of Swiss Confederation bond yields allows us to decompose, in real time, long-term yield changes into changes to expected short-rate and term premium components. ${ }^{7}$ The expected short-rate component is then associated with monetary policy expectations, or signaling, while portfolio balance effects are associated with the term premium component. As mentioned above, supply- and reserve-induced portfolio balance effects cannot be separately identified in the term premium. But given the special nature of the SNB program, we interpret the changes in the Swiss term premium in response to the announcements of the reserve expansions as primarily representing reserve-induced portfolio balance effects.

We find that the identified drop in long-term Swiss Confederation bond yields predominantly reflected a drop in the term premium, suggestive of reserve-induced portfolio balance

\footnotetext{
${ }^{6}$ Apart from being able to compare with the previous literature on the effects of QE on long-term bond yields, our focus on Swiss government bond yields is also motivated by the findings of Ranaldo and Rossi (2010), who study the response of various Swiss financial assets to SNB monetary policy announcements. They find that the bond market shows strong reactions to such events. This suggests that a focus on Swiss Confederation bonds will provide the clearest reading of investors' reactions to the SNB announcements.

${ }^{7}$ Gagnon et al. (2011), CR, and Bauer and Rudebusch (2014) are among the previous studies that provide term structure model decompositions of the US experience with unconventional monetary policies. Mirkov and Sutter (2013) also use term structure models to analyze both the US and Swiss experience with such policies, but they do not make a real-time event study like ours.
} 
effects. By contrast, we find signaling effects to have been less important in driving the response of long-term yields to the SNB's announcements.

The findings are robust as they survive a number of robustness checks. First, we use regression analysis to control for foreign and financial market developments more broadly. This only reduces the estimated drop in the term premium slightly. Second, we do a thorough search for other events that could have led to the yield declines, but fail to find any overlapping with the SNB event windows. Finally, we investigate related intraday data, which shows a pattern and timing consistent with the results from the daily model estimations.

To the best of our knowledge, this paper is the first to show, using data on unconventional monetary policies in the aftermath of the global financial crisis, that an expansion of reserves can result in significant portfolio balance effects on long-term bond yields in the absence of any long-term bond purchases.

These findings have important policy implications. They suggest that it is possible to design effective QE programs with the aim of influencing long-term interest rates in economies where institutional or market factors preclude outright large-scale central bank purchases of long-lived securities. Purchases of shorter-term bonds or other assets may still reduce longterm yields. Moreover, when exiting existing QE programs, the management of the size of reserves by itself could warrant as much attention as the wind-down of the portfolio of purchased assets.

The remainder of the paper is structured as follows. Section 2 discusses the channels of transmission of $\mathrm{QE}$ to long-term interest rates, paying special attention to the proposed reserve-induced portfolio balance channel. Section 3 describes the SNB's three expansions of reserves in August 2011. Section 4 contains the model-based event analysis of the market reaction around the SNB announcements. In Section 5, we carry out several robustness checks, while Section 6 concludes. Appendices contain additional empirical results, technical formulas, and event information.

\section{The Reserve-Induced Portfolio Balance Channel}

In this section, we describe in more detail the mechanics of the reserve-induced portfolio balance channel, and how it relates to the two standard transmission channels of QE. 


\subsection{Standard Transmission Channels of QE to Long-Term Rates}

In the term structure literature, it is standard to decompose the yield of a bond into a risk-neutral component that equals the average expected future short-term money market or policy interest rates until maturity, and a residual term premium component that represents investors' required compensation for the added risk of buying a fixed-income bond of a given maturity instead of investing the same amount in the short-term money market:

$$
y_{t}(\tau)=\frac{1}{\tau} \int_{t}^{t+\tau} E_{t}^{P}\left[r_{s}\right] d s+T P_{t}(\tau)
$$

where $t$ is time and $\tau$ is time until maturity. $R N_{t}(\tau)=\frac{1}{\tau} \int_{t}^{t+\tau} E_{t}^{P}\left[r_{s}\right] d s$ is the risk-neutral component of the yield that is identical for all bonds of that maturity independent of the issuer. The term premium, $T P_{t}(\tau)$, captures macro risks such as uncertainty regarding the growth and inflation outlook, changes in overall risk aversion, issuer-specific risks such as the credit risk of the issuer in question, and liquidity risk of the bond. Finally, it also captures a premium due to supply and demand factors in the market for this particular bond in the presence of market imperfections.

Central bank asset purchases and their associated reserve expansions can affect both components of the yield. First, the news that such measures are needed may change private agents' expectations about the future intentions of the central bank in terms of the path of short-term policy rates, which in turn would affect the risk-neutral part of the yield, $R N_{t}(\tau)$. Such effects are referred to as signaling effects in the literature.

Furthermore, QE measures may change the supply of or demand for a given asset, which would affect its price and hence risk premium. Such effects are usually referred to as portfolio balance effects. ${ }^{8}$ The seminal model for portfolio balance effects was devised by Vayanos and Vila (2009). This model suggests that, when assets with otherwise near-identical risk and return characteristics are considered imperfect substitutes by some market participants (e.g., due to preferred habitat) and markets are segmented, a change in the relative market supply of an asset may affect its relative price (see also Tobin, 1969). Consistent with this model the existing literature on the impact of QE on yields has treated central bank asset purchases as a reduction in the market supply of the targeted assets. When a central bank buys long-term government bonds on a large scale, their available stock for trading in the market is reduced. For market participants to accept selling and holding less of the bonds, their prices have to

\footnotetext{
${ }^{8}$ This clean division into signaling and portfolio balance effects is a simplification, and interactions between the two components are likely to occur. See Bauer and Rudebusch (2014) for a thorough discussion.
} 
increase relative to those of other assets. As a result, long-term yields drop.

\subsection{Reserve-Induced Portfolio Balance Effects}

An overlooked but potentially important aspect of central bank large-scale asset purchases is the fact that the purchases are paid for with new issues of central bank reserves. Bernanke and Reinhart (2004) suggest that this expansion of reserves may also produce portfolio balance effects on asset prices. In the existing literature, the possibility of such effects has yet to be explored. The much-cited model by Vayanos and Vila (2009) cannot account for such effects. It contains neither a central bank balance sheet nor central bank reserves, and it does not distinguish between banks and non-banks and their different roles in allocating central bank short-term liquidity. Moreover, it does not incorporate the feature that only banks can hold reserves with the central bank.

To understand the transmission mechanism of central bank reserve expansions to longterm interest rates, a theoretical framework should, at a minimum, include a central bank balance sheet, deposit taking and reserve holding banks, and non-bank financial institutions with bank deposits as assets. Such a theoretical framework has yet to be developed. In the following, we give a stylized example of the transmission mechanism we propose for how expansions of reserves can affect long-term yields independently of the assets purchased by the central bank.

To keep it as simple as possible, consider a financial system consisting of a banking sector, a non-bank financial sector, and a central bank. Figure 1 illustrates the stylized aggregate balance sheets for these three groups of agents. In this economy, there are four types of financial instruments, namely short-term bills, long-term bonds, deposits, and reserves. On the supply side, bills and bonds are in fixed supply, while the central bank has a monopoly on issuing reserves and only banks can issue deposits. On the demand side, both banks and non-banks can hold deposits, bills and bonds. Only banks can hold reserves, however.

Within this framework we consider the portfolio response of banks and non-banks to central bank asset purchases over a period of time sufficiently short so that banks do not adjust their credit portfolios to changes in funding conditions. We think this is a realistic description of banks' immediate reaction to announcements of QE programs in the various countries where such programs have been employed in the wake of the global financial crisis, and hence, a relevant example for thinking about the market impact of QE. Over the longer term, banks would eventually adjust their credit portfolios and the economy would respond 


\begin{tabular}{|ll|}
\hline \multicolumn{2}{|c|}{ Banks } \\
Assets & Liabilities \\
\hline Reserves $\uparrow$ & Equity \\
Short bonds & Deposits 1 \\
Long bonds & Other debt \\
Other assets & \\
\hline
\end{tabular}

\begin{tabular}{|ll|}
\hline \multicolumn{2}{|c|}{ Central Bank } \\
Assets & Liabilities \\
\hline Short bonds 1 & Equity \\
Long bonds & Reserves 1 \\
Other assets & Other liabilities \\
& \\
\hline
\end{tabular}

\begin{tabular}{|ll|}
\hline \multicolumn{2}{|c|}{ Non-Bank Financial Firms } \\
Assets & Liabilities \\
\hline Deposits & Equity \\
Short bonds & Debt \\
Long Bonds & \\
Other assets & \\
\hline
\end{tabular}

Figure 1: Balance Sheets of Key Financial Market Participants.

Stylized balance sheets of three key players in financial markets: the central bank, reserve holding banks, and non-bank financial institutions. The central bank can transact with both types of institutions.

accordingly. Here, we do not consider such longer-term or general equilibrium effects, as we are interested in the immediate reaction of interest rates to central bank asset purchases.

To begin, we consider the case of a central bank that conducts QE by purchasing shortterm bills from the market. We assume short-term bills and reserves to be near-perfect substitutes from the point of view of reserve holding banks, and that both instruments carry a near-zero interest rate. To further simplify the example, we also assume that non-bank financial institutions consider bank deposits and short-term bills to be near-perfect substitutes near the zero lower bound. This assumption is less realistic and clearly disregards differential credit risk profiles and other features that might otherwise distinguish these assets. As we argue below, however, this assumption helps us to ensure that any relative changes in the market supply of the purchased assets do not lead to any supply-induced portfolio balance effects on asset prices. If we nevertheless observe an effect on long-term yields from the central bank swapping reserves for short-term bills, this would have to come about through a reserve-induced effect.

The red arrows in Figure 1 show what happens to the central bank balance sheet when it purchases short-term bills from the market in exchange for reserves. Its assets increase with 
the amount of short-term bonds purchased, while its liabilities go up with the same amount of reserves.

Now, there are two alternatives to consider depending on the counterparties to the transactions. First, assume that the counterparties to the central bank's transactions happen to be banks exclusively. This would for example be the case if banks' demand for such bonds had a high price elasticity, while the price elasticity of the demand of non-bank financial institutions would be very low. In this case, the corresponding portfolio changes on banks' balance sheets are given by the green arrows in Figure 1. In the aggregate, banks' balance sheets are left unchanged, but the composition of short-term assets shifts from short-term bills toward reserves. As long as these two types of assets are considered near-perfect substitutes, this "asset swap" would not change banks' portfolio composition or duration. Also, banks' liabilities would remain unchanged. Hence, there would be no need for banks to adjust their portfolios and no asset prices would change. This is indeed the standard argument against portfolio balance effects of short-term asset purchases when the conventional policy rate is stuck near the zero lower bound.

Consider now the alternative situation when the central bank purchases short-term bills mainly from non-bank financial firms. This would for example be the case if non-bank financial firms' demand for short-term bills have a higher price elasticity than the demand by the banks. The balance sheet implications of central bank transactions with the non-bank financial sector are shown with black arrows in Figure 1. Since non-bank financial firms cannot accept reserves as payment directly, the central bank credits the reserves with the correspondent banks, which then credit the deposits held by the non-bank financial firms. Under our asset substitutability assumptions, the balance sheets and portfolio compositions of the non-bank financial firms would be largely unchanged and not provide incentives to engage in any portfolio adjustments. In short, there are no supply-induced portfolio balance effects arising from such central bank purchases.

The same is not true for the banks' aggregate balance sheet, which, as a result of their customers' transactions, has grown on the asset side by the amount of new reserves and on the liability side by the new deposits. Critically, banks have had no say in these transactions that they are obliged to carry out on behalf of their customers. Note that there is no reason why the transactions should be undone by banks selling short-term bills to non-banks in exchange for the deposits, if the non-banks sold their bills to the central bank in the first place because of their greater preference to do so. 
Assuming banks considered their asset allocation and portfolio duration optimal before this autonomous balance sheet expansion, and also assuming that the newly issued deposits are considered a stable source of funding at the aggregate level of the banking sector, then it is unlikely that banks would view their new asset allocation and duration as optimal. Core funding has gone up. The unweighted capital ratio has declined, but the weighted capital ratio has not changed. As a consequence, banks' portfolios have become more heavily tilted toward safe, liquid, and low-yielding reserves and their average duration has declined.

In response, banks may individually try to diversify out of excess reserves and into other assets. In the aggregate, however, banks must hold the reserves created by the central bank's open market operations. They can only sell reserves to each other. Banks may hence seek to purchase assets from each other using reserves, and banks will individually have an incentive to continue doing this until relative asset prices have adjusted sufficiently for individual banks to be content holding the increased amount of reserves. With reserves being the numeraire currency, their price cannot change. Instead, the prices of other assets in banks' portfolios must go up for banks to be willing to hold a greater amount of zero-duration low-yielding reserves relative to other assets. In principle, the prices of all securities held by banks in their financial asset portfolios could be affected according to this logic.

Bank regulation could affect the portfolio response of banks to reserve-induced balance sheet expansions. If, for example, banks are constrained by weighted capital adequacy ratios, such as the Basel II capital adequacy rules, it is possible that banks would predominantly seek to substitute away from low-yielding reserves and into higher-yielding assets with zero risk weights, such as government bonds. A downward pressure on the yields of such assets would ensue. In contrast, if an unweighted leverage ratio is constraining banks' balance sheets, the initial reserve-induced balance sheet expansion could instead lead to a need for banks to selloff assets (deleverage), or a need to raise new equity combined with a shift into higher yielding assets. The effect on yields is in this case unclear. This point also raises the possibility that the introduction and binding nature of a leverage ratio may substantially change the way that $\mathrm{QE}$ is transmitted to interest rates. As a result, the reserve-induced effect of QE depends on the prevailing market and regulatory circumstances of banks and non-bank financial firms. In the end, the response of banks and asset prices is an empirical question.

By construction, our stylized balance sheet example excludes the existence of standard supply-induced portfolio balance effects. The example shows that QE can affect long-term interest rates and other asset prices, even when no long-term assets are bought, through the 
reserve-induced portfolio balance channel. If the central bank instead buys long-term bonds for reserves from the non-bank private sector, both channels could be active and reinforce each other. There would be less long-term bonds on non-bank financial firm balance sheets, which would lead to standard supply-induced portfolio balance effects on the price of longterm bonds. At the same time, the purchases from non-bank financial firms would result in a reserve-induced expansion of banks' balance sheets, which in turn could lead to reserveinduced portfolio balance effects on long-term yields if the circumstances are right. This latter effect is independent of whichever assets the central bank purchases in order to achieve the expansion. ${ }^{9}$

\subsection{Identification of Reserve-Induced Portfolio Balance Effects}

The QE programs in the US and the UK in recent years have been carried out predominantly through purchases of long-term assets. As a consequence, they could have given rise to both supply- and reserve-induced portfolio balance effects. In either case, the effects would materialize upon the announcement of the programs. Hence, an event study would not be able to separately identify the two effects.

In order to empirically identify reserve-induced portfolio balance effects on long-term yields, we need a QE program that was carried out without any purchases of long-term assets. If such a program nevertheless had portfolio balance effects on long-term yields, this would be evidence of reserve-induced portfolio balance effects.

The Swiss reserve expansions in August 2011 distinguish themselves from the QE programs carried out in the US and the UK by having been achieved without purchases of long-term assets. They hence provide a unique case study where reserve-induced portfolio balance effects on long-term yields can be separately identified. The Swiss case is additionally interesting because the conditions for this program to have had reserve-induced effects are likely to be fulfilled. First, risk-weighted assets arguably represented an important balance sheet constraint for Swiss bank portfolio choice during the time when the SNB program was announced and enacted. Second, the size of the reserve expansions was large relative to both the Swiss Confederation bond market (around 100 billion Swiss francs (CHF) in outstanding notional in recent years) and banks' holdings thereof (Swiss banks held about CHF 11 billion of these bonds in 2011). ${ }^{10}$ If only a fraction of the reserve injections in 2011 resulted in higher

\footnotetext{
${ }^{9}$ Provided the policy goal is to achieve maximum impact on long-term yields, this logic clearly favors QE programs with purchases of long-term securities as in the US and the UK.

${ }^{10}$ Foreign banks with sight deposits at the SNB could have held additional Confederation bonds. Data on Confederation bond supply and bank holdings are available in the annual Swiss National Bank publications
} 
bank demand for Confederation bonds, the effect on the relatively small Confederation bond market could be substantial.

\section{The SNB's Expansion of Reserves in August 2011}

In normal times, the SNB aims for price stability by setting a target range for a representative short-term money market interest rate, the three-month CHF LIBOR, and by steering market rates toward this target through short-term repo operations. The exchange rate is floating under normal circumstances. This policy framework reached its limit in March 2009 when, in response to developments related to the financial crisis, the SNB reduced its target rate to what was at the time considered its effective lower bound. Further monetary policy easing continued to be desirable, in particular because of the persistent strengthening of the Swiss franc due to sustained safe-haven pressures starting in late 2008, shown in Figure 2(a). The appreciation added considerable downward pressure on Swiss consumer prices despite the low interest rate level. In response, the SNB adopted a number of unconventional policies. In March 2009, these included foreign exchange interventions to prevent further appreciation, extension of the maturity for repo operations, and a relatively small, targeted, and short-lived bond purchase program. ${ }^{11}$

The bond purchase program was discontinued by the end of 2009, and foreign exchange interventions were officially discontinued in the summer of 2010. By that time, however, the foreign exchange interventions had resulted in a substantial expansion of the SNB's balance sheet and central bank reserves. A large part of these reserves were gradually absorbed starting in 2010, through reverse repo operations and through the sale of short-term central bank bills, referred to as SNB bills. ${ }^{12}$ Still, the exchange rate continued to appreciate. In 2011, the intensification of the European debt crisis compounded woes and resulted in an increasing risk of severe deflation in Switzerland.

Against this background, the SNB introduced the new unconventional policy measures in August that are the focus of this paper. First, on August 3, the SNB announced that it would further lower the top of the target range for the three-month CHF LIBOR from 75 to 25 basis points (the bottom of the range was already at zero), and that it would aim at the lower end of the range. At the same time, it announced that it would significantly increase its supply of

\footnotetext{
"Banks in Switzerland" and "Swiss Financial Accounts."

${ }^{11}$ See Kettemann and Krogstrup (2014) for an overview and analysis of the impact of this program.

${ }^{12} \mathrm{SNB}$ bills are short-term debt securities with maturities up to one year issued by the SNB.
} 


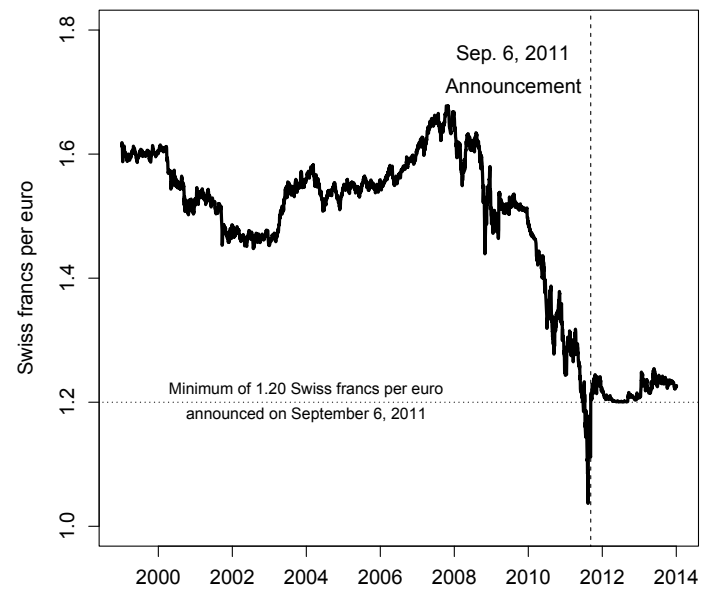

(a) $1999-2014$.

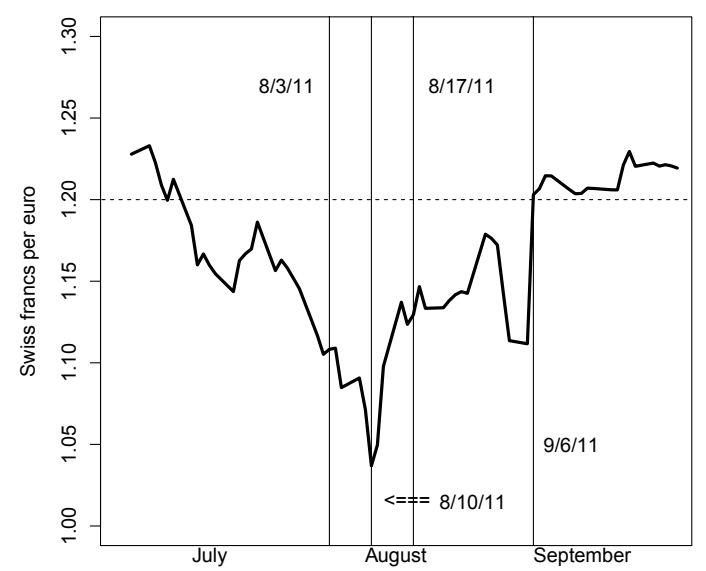

(b) July to September 2011.

Figure 2: The Exchange Rate between the Swiss Franc and the Euro.

Panel (a) shows the daily movements in the exchange rate between the Swiss franc and the euro since 1999. Panel (b) shows the daily movements around the four 2011 SNB unconventional policy announcements, indicated with vertical lines. In both panels, the minimum exchange rate level of 1.20 announced on September 6, 2011, is shown with a dotted black horizontal line. Source: SNB.

liquidity to Swiss money markets. ${ }^{13}$ Specifically, the SNB would expand banks' sight deposits (i.e., central bank reserves) from CHF 30 billion to CHF 80 billion. ${ }^{14}$ The stated intention was to push down money market interest rates, thereby making the Swiss franc less attractive to hold against other currencies. No intentions of affecting long-term yields or risk premiums were stated.

The reserve expansion was to be achieved by buying back SNB bills from the markets, by not rolling over maturing SNB bills, and by allowing reverse repos with banks to expire. The intended mix of these operations was not announced, and could only be observed ex post. As shown in Figure 2(b), the exchange rate appreciation briefly paused, but quickly resumed following this first announcement.

One week later, on August 10, the SNB announced that it would again expand reserves, this time by an additional CHF 40 billion. ${ }^{15}$ To achieve the second expansion quickly, the

\footnotetext{
${ }^{13}$ See the press release at http://www.snb.ch/en/mmr/reference/pre_20110803/source/pre_20110803.en.pdf.

${ }^{14}$ Banks' sight deposits are equivalent to central bank reserves. Approximately 300 banks hold sight deposits at the SNB. Sight deposits were non-interest bearing at the time, and readily available for payment transactions and represent legal payment instruments. Banks also hold sight deposits as a liquidity reserve and in order to fulfill the statutory minimum reserve requirements. The SNB directly influences the aggregate amount of sight deposits, and hence the liquidity in the Swiss franc money market, through its money market operations. Total SNB sight deposits also include deposits held by the Swiss government and a smaller number of non-bank financial institutions.

${ }^{15}$ See the press release at http://www.snb.ch/en/mmr/reference/pre_20110810/source/pre_20110810.en.pdf.
} 


\begin{tabular}{lll}
\hline No. & Date & Announcement description \\
\hline I & Aug. 3, 2011, 8:55 a.m. & $\begin{array}{l}\text { Target range for three-month CHF LIBOR lowered to 0 } \\
\text { to 25 basis points. In addition, banks' sight deposits at } \\
\text { the SNB will be expanded from CHF 30 billion to CHF 80 } \\
\text { billion. }\end{array}$ \\
II $\quad$ Aug. 10, 2011, 9:05 a.m. & $\begin{array}{l}\text { Banks' sight deposits at the SNB will rapidly be expanded } \\
\text { from CHF 80 billion to CHF 120 billion. }\end{array}$ \\
III Aug. 17, 2011, 8:55 a.m. & $\begin{array}{l}\text { Banks' sight deposits at the SNB will immediately be ex- } \\
\text { panded from CHF 120 billion to CHF 200 billion. }\end{array}$ \\
& Sep. 6, 2011, 10:00 a.m. & $\begin{array}{l}\text { The SNB announces a minimum exchange rate for the } \\
\text { Swiss franc to the euro of 1.20 francs per euro and is pre- } \\
\text { pared to buy foreign currency in unlimited quantities to } \\
\text { defend it. }\end{array}$ \\
\hline
\end{tabular}

Table 1: SNB Policy Announcements in August and September 2011.

SNB would, in addition to the previous types of operations, also conduct short-term foreign exchange swaps (primarily of one week maturity). The exchange rate reversed course and briefly depreciated following this announcement. The depreciation was not considered sufficient, however, and on August 17, the SNB announced it would increase reserves further, this time by an additional CHF 80 billion. This final expansion would take the total level of reserves to roughly CHF 200 billion. ${ }^{16}$

The exchange rate response was again muted. In the weeks that followed, the appreciation resumed. Therefore, on September 6, the SNB adopted a minimum exchange rate for the Swiss franc of 1.20 francs per euro, and stated its willingness to buy foreign currency in unlimited quantities to defend this minimum exchange rate. ${ }^{17}$ The exchange rate immediately moved to 1.20 and remained at or above this threshold until January 15, 2015, when the minimum exchange rate policy was abandoned.

Our focus is on the three expansions of reserves announced in August 2011 (events I-III in Table 1). The sum of these reserve expansions amounted to CHF 170 billion, or about 30 percent of Swiss GDP in 2011. In comparison, the US aggregate QE programs have yet to reach such a magnitude. ${ }^{18}$ Figure 3 shows the reserve expansions and their main counterparts on the SNB balance sheet. A large part was achieved by repurchasing SNB bills and allowing SNB bills to mature without new issuance. The total volume of outstanding

\footnotetext{
${ }^{16}$ See the press release at http://www.snb.ch/en/mmr/reference/pre_20110817/source/pre_20110817.en.pdf.

${ }^{17} \mathrm{See}$ the press release at http://www.snb.ch/en/mmr/reference/pre_20110906/source/pre_20110906.en.pdf.

${ }^{18} \mathrm{As}$ of the end of 2013, the Federal Reserve's balance sheet totaled $\$ 4.1$ trillion, or about 25 percent of US GDP.
} 


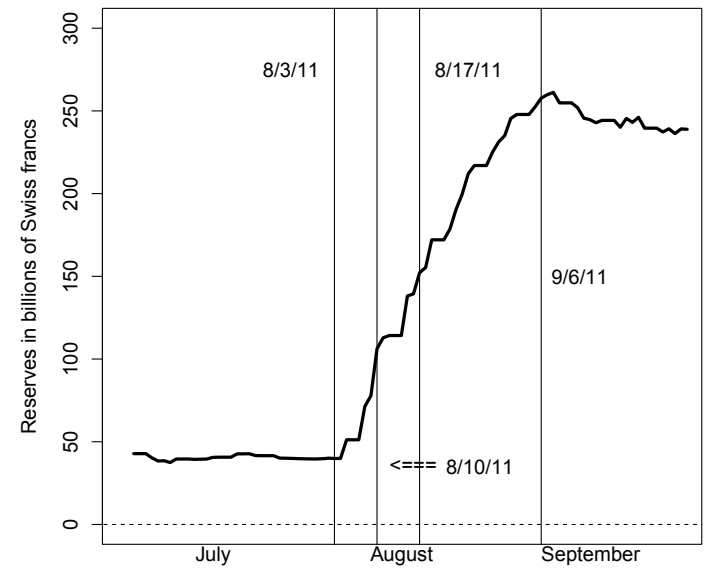

(a) Total SNB reserves.

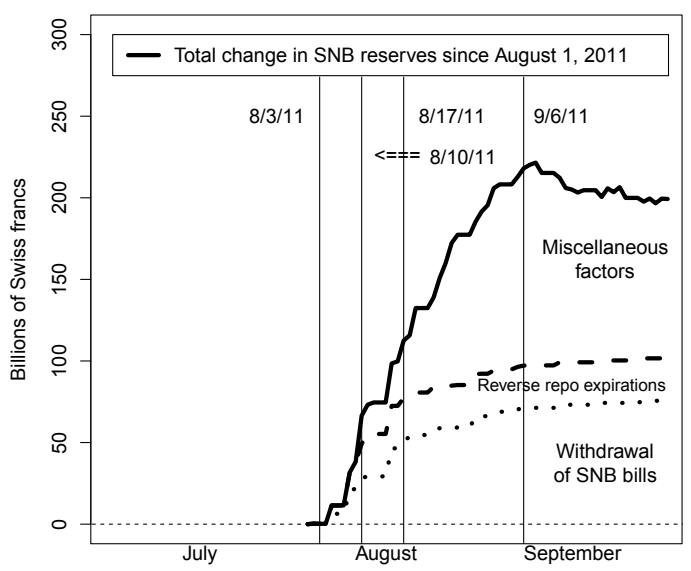

(b) Decomposition of changes in reserves.

Figure 3: Expansion of Reserves and Counterparts on the SNB Balance Sheet.

Panel (a) shows the daily total SNB reserves in billions of Swiss francs around the four SNB unconventional policy announcements shown with solid black vertical lines. Panel (b) decomposes the changes in total SNB reserves from August 1, 2011, through September 2011 into (i) withdrawal of SNB bills (through expiration or repurchases), (ii) reverse repo expirations, and (iii) miscellaneous residual factors that include outright foreign currency purchases and foreign exchange swaps. Source: SNB.

bills was reduced by CHF 66 billion in August alone. By the end of 2011, outstanding bills had been reduced by nearly CHF 100 billion. Expiration of reverse repos amounted to CHF 26 billion in August, after which all reverse repo operations had expired. Liquidityincreasing repos were subsequently carried out, but these contributed only a small part of the overall reserve expansion. The largest part of the expansions in August was achieved through other measures, most notably foreign exchange swaps. These foreign exchange swaps were in short maturities, between one week and one month. The foreign exchange proceeds from the swaps were either kept in foreign official accounts or invested in short-term liquid foreign assets for the duration of the swap. Short-term foreign exchange swaps used to be the SNB's main monetary policy instrument for implementing its monetary targets before moving to an interest rate target in the early 2000s. The Swiss were hence familiar with such transactions as a domestic money market instrument, and did not mistake them for foreign exchange interventions in disguise. As SNB bills were increasingly bought back during the rest of 2011, a corresponding part of the foreign exchange swaps were allowed to expire.

Figure 4 shows the movements of the daily ten-year Swiss Confederation bond yield during the summer and early fall of 2011, and the dates of the three announcements of reserve 


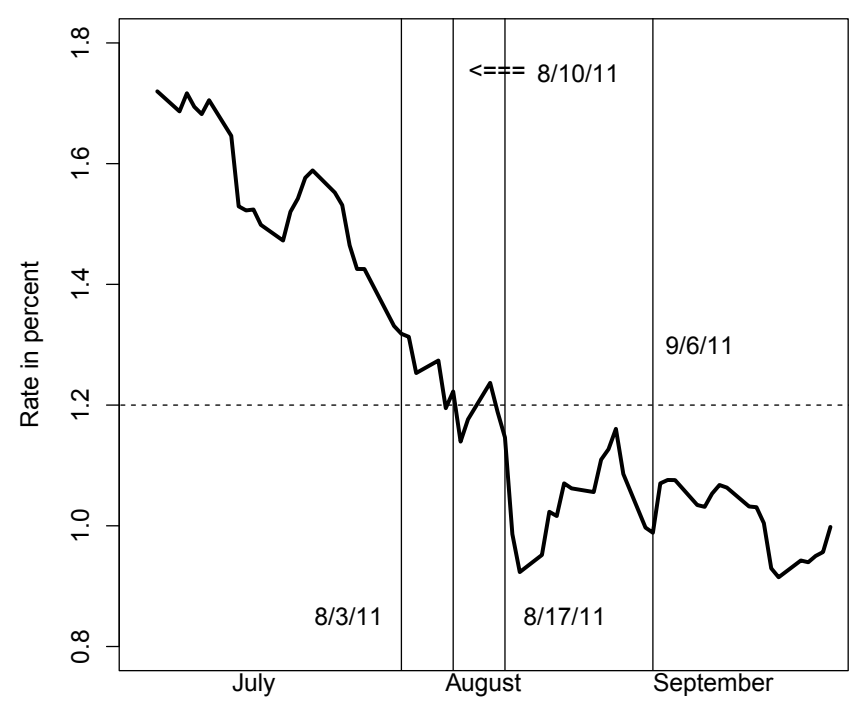

Figure 4: Ten-Year Swiss Confederation Bond Yield.

Illustration of the movements in the ten-year Swiss Confederation bond yield around the SNB policy announcements in August and September 2011, shown with solid black vertical lines. Source: SNB.

expansions as well as the date on which the minimum exchange rate was introduced. The yield was already on a downward trend due to strong global safe-haven pressures and high risk aversion when the first announcement was made. During the weeks of the three announcements, however, the drop in the yield accelerated. Moreover, yields invariably fell following all three announcements. In Section 4, we report that yields dropped by a collective 28 basis points following the three announcements. The drop in response to the last and most forceful announcement was the strongest and most significant.

To be able to learn something from the market response to these announcements using an event study, at least part of these measures must have been unexpected when they were announced. We therefore briefly address this issue here. Clearly, the public was expecting a monetary policy reaction to the worsening situation in August 2011. There was plenty of discussion in the Swiss media and a certain level of pressure from political and interest groups to enact measures to counter what was seen as an unsustainable and unacceptable exchange rate appreciation in the spring and early summer of 2011. The public called for a floor or peg for the exchange rate, or for interventions to reverse the exchange rate trend. There was also speculation about the SNB introducing negative interest rates, and for good reasons. The SNB had responded to a strongly appreciating exchange rate in the 1970s by introducing 
negative interest rates on foreign bank deposits, before finally introducing an exchange rate floor to the German mark in 1979. Still, the timing, specific nature, and content of the announcements were very likely to have been unexpected for several reasons. First, the three announcements followed unscheduled and unannounced meetings of the SNB's Governing Board. ${ }^{19}$ Second, the public debate before the announcements did not include any discussion of possible liquidity expansions. Reserve expansions had never been used as a policy tool by the SNB, nor had it ever been publicly discussed as a possible means to counter exchange rate appreciation pressures. Third, the sheer size of the expansions seems to have been a complete surprise. Thus, the SNB announcements appear to satisfy the requirements for a classic event study of the type we perform in the next section.

\section{Empirical Analysis}

In this section, we first describe the event study method we employ to analyze the effects of the SNB announcements. We then detail the Swiss government bond yield data used in the analysis and describe how these bond yields can be decomposed into a short-rate expectations component and an associated term premium component. We further introduce the specific class of Gaussian term structure models we use for that purpose and proceed to find a preferred specification and document its performance. We end the section by performing a real-time decomposition of the yield responses to the SNB announcements into separate short-rate expectations and term premium components.

\subsection{Event Study Methodology}

Since bond prices, like other asset prices, are the result of transactions between forwardlooking investors, any potential portfolio balance effects will be reflected in bond prices at the time investors become aware of a future change to relative asset demands and supplies. The price impact thus occurs not when a policy is implemented but when it is revealed to the public (the two may coincide, of course). As a consequence, we limit our study to an event analysis of the SNB announcements in August 2011 assuming that they contained new information for financial market participants about the relative demand and supply of assets going forward.

We use a two-day window as the baseline for the event study, in line with the literature (see,

\footnotetext{
${ }^{19}$ The SNB normally releases its monetary policy statements on a scheduled quarterly basis in mid-March, mid-June, mid-September, and mid-December.
} 
e.g., Joyce and Tong, 2012). A broad window is necessary because we do not know exactly when, during the morning, the yield data we use are collected (further details about the data are provided below). The bond data could have been collected at the same time, around 09:00 a.m., or several hours after the announcements were made. Moreover, we need to allow market participants sufficient time to process and factor in the new information contained in the unusual announcements. In fact, results reported in Appendix $\mathrm{C}$ show that, for all three announcements, the yield responses between the morning before the announcements and the recording of the data on the morning of the announcements are rather small.

Ranaldo and Rossi (2010) find that, in the past, Swiss bond markets have taken up to 30 minutes to respond to conventional, and hence familiar, types of SNB policy announcements. The event window should allow for at least this amount of time for markets to react. By investigating the change between the morning of the day before the announcements and the morning of the day after the announcements, we allow for a minimum of 24 hours, but no more than 26 hours, for the response to materialize after each announcement.

The drawback of a broad event window is a higher risk of including news not related to the event. In the robustness section to follow, we therefore carefully consider whether other events took place during the event windows which could be driving our results. Furthermore, the event study technique suffers from the fact that we cannot accurately assess what was expected before each announcement. As discussed above, some action was likely expected by market participants before the announcements, although the specific nature of the announcements was likely to have been a surprise. This could result in some degree of underestimation of the interest rate response.

\subsection{Daily Data on Confederation Bond Yields}

We now describe the yield data derived from Swiss Confederation bonds and used in the empirical analysis, and take a second look at how yields behaved in the event windows around the three policy announcements.

The specific Swiss bond yields analyzed in this paper are zero-coupon yields constructed using a smooth discount function based on the Svensson (1995) yield curve: ${ }^{20}$

$$
y(\tau)=\beta_{0}+\frac{1-e^{-\lambda_{1} \tau}}{\lambda_{1} \tau} \beta_{1}+\left[\frac{1-e^{-\lambda_{1} \tau}}{\lambda_{1} \tau}-e^{-\lambda_{1} \tau}\right] \beta_{2}+\left[\frac{1-e^{-\lambda_{2} \tau}}{\lambda_{2} \tau}-e^{-\lambda_{2} \tau}\right] \beta_{3} .
$$

\footnotetext{
${ }^{20}$ These are computed daily by SNB staff.
} 


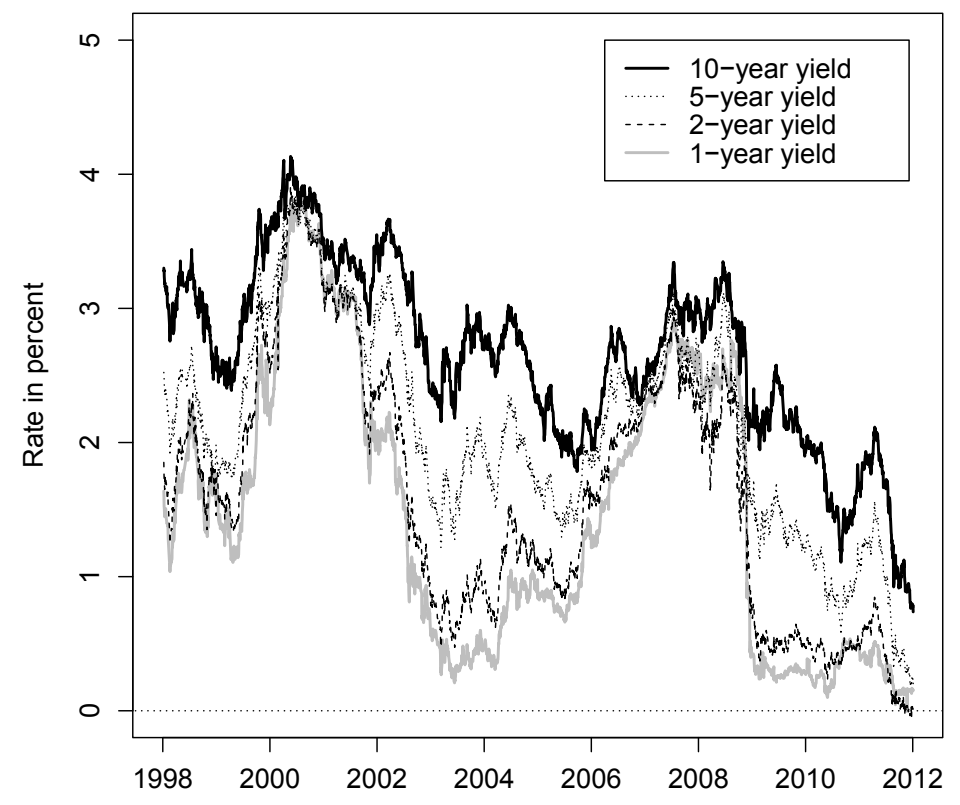

Figure 5: Time Series of Swiss Government Bond Yields.

Illustration of the daily Swiss government zero-coupon bond yields covering the period from January 6, 1998, to December 30, 2011. The yields shown have maturities in one year, two years, five years, and ten years, respectively.

For each business day, this function is used to price a set of observed Swiss Confederation bond prices. The zero-coupon yields derived from this approach should constitute a very good approximation to the true underlying Swiss government zero-coupon bond yield curve over the maturity range covered by the underlying pool of bonds. ${ }^{21}$

Using the fitted values of the four coefficients, $\left(\beta_{0}(t), \beta_{1}(t), \beta_{2}(t), \beta_{3}(t)\right)$, and the two parameters, $\left(\lambda_{1}(t), \lambda_{2}(t)\right)$, we obtain zero-coupon bond yields with six maturities: one, two, three, five, seven, and ten years to maturity. The summary statistics are provided in Table 2, while Figure 5 illustrates the constructed time series of the one-, two-, five-, and tenyear Swiss government zero-coupon bond yields. The figure shows that the term structure is upward sloping on average, and that short- and medium-term yields are more volatile than long-term yields. These are stylized facts shared by both US Treasury and UK gilt yield data.

Table 3 shows the two-day response of the Swiss government bond yields to the SNB announcements. As noted in Section 3, there is a clear negative yield response, on net, to

\footnotetext{
${ }^{21}$ See Gürkaynak et al. (2007) for evidence of the accuracy of the Svensson (1995) curve when applied to US data.
} 


\begin{tabular}{ccccc}
\hline $\begin{array}{c}\text { Maturity } \\
\text { (months) }\end{array}$ & $\begin{array}{c}\text { Mean } \\
\text { (percent) }\end{array}$ & $\begin{array}{c}\text { Std. dev. } \\
\text { (percent) }\end{array}$ & Skewness & Kurtosis \\
\hline 12 & 1.46 & 1.03 & 0.44 & 2.01 \\
24 & 1.62 & 0.96 & 0.34 & 2.17 \\
36 & 1.78 & 0.90 & 0.21 & 2.25 \\
60 & 2.10 & 0.79 & 0.01 & 2.46 \\
84 & 2.36 & 0.72 & -0.14 & 2.67 \\
120 & 2.65 & 0.68 & -0.32 & 2.82 \\
\hline
\end{tabular}

Table 2: Summary Statistics for the Swiss Government Bond Yields.

Summary statistics for the sample of daily Swiss government zero-coupon bond yields covering the period from January 6, 1998, to December 30, 2011, a total of 3,475 observations.

the announcements with long-term yields declining about twice as much as their shorter-term counterparts. ${ }^{22}$

Focusing on the ten-year yield, the drop of a few basis points following the first announcement was within one standard deviation of two-day yield changes during the sample period (about 5 basis points). However, the change in the yield following the second announcement was slightly above. The yield drop was particularly strong in connection with the final and most forceful announcement. The ten-year yield fell by 20 basis points between the morning of the day before and the morning of the day after that announcement, amounting to four standard deviations of two-day changes in that yield over our sample period. ${ }^{23}$ By contrast, the exchange rate barely reacted, making it unlikely that the movements in yields were driven by exchange rate changes. ${ }^{24}$

We now address the question of whether these drops reflected expected future policy rates or term premiums. For this, we need to decompose yields into term premiums and expected future short rates.

\footnotetext{
${ }^{22}$ Daily Bloomberg data for the mid-market yield to maturity of the $2 \%$ Swiss Confederation bond with maturity on May 25, 2022, are consistent with the magnitude of the reported declines in long-term yields.

${ }^{23}$ For the entire sample period since 1998, only one two-day change was larger than that observed on August 17. That extreme event took place on November 20, 2008, in connection with the global financial market turmoil following the Lehman Brothers bankruptcy. At that time, the ten-year yield fell 29 basis points over two days.

${ }^{24}$ Note that, if the measure announced on August 17, 2011, led market participants to believe more strongly that the SNB would take measures to induce the exchange rate to depreciate in the future, we should have expected to see an increase in the yield to compensate for the expected depreciation risk according to interest rate parity conditions.
} 


\begin{tabular}{llcccccc}
\hline \multirow{2}{*}{ Event } & \multicolumn{6}{c}{ Maturity } \\
\cline { 3 - 8 } & & 1-year & 2-year & 3-year & 5 -year & 7-year & 10-year \\
\hline \multirow{2}{*}{ I } & Aug. 2, 2011 & 30 & 17 & 24 & 65 & 100 & 133 \\
& Aug. 4, 2011 & 26 & 12 & 20 & 61 & 98 & 131 \\
\cline { 2 - 8 } & Change & $\mathbf{- 4}$ & $\mathbf{- 5}$ & $\mathbf{- 5}$ & $\mathbf{- 4}$ & $\mathbf{- 3}$ & $\mathbf{- 2}$ \\
\hline \multirow{3}{*}{ II } & Aug. 9, 2011 & 26 & 13 & 14 & 47 & 83 & 119 \\
& Aug. 11, 2011 & 21 & 8 & 10 & 43 & 79 & 114 \\
\cline { 2 - 8 } & Change & $\mathbf{- 5}$ & $\mathbf{- 5}$ & $\mathbf{- 5}$ & $\mathbf{- 4}$ & $\mathbf{- 4}$ & $\mathbf{- 6}$ \\
\hline \multirow{2}{*}{ III } & Aug. 16, 2011 & 19 & 8 & 13 & 49 & 84 & 119 \\
\cline { 2 - 8 } & Aug. 18, 2011 & 18 & 8 & 7 & 32 & 64 & 99 \\
\cline { 2 - 8 } & Change & $\mathbf{0}$ & $\mathbf{0}$ & $\mathbf{- 6}$ & $\mathbf{- 1 7}$ & $\mathbf{- 2 1}$ & $\mathbf{- 2 0}$ \\
\hline \multirow{2}{*}{ Total net change } & $\mathbf{- 9}$ & $\mathbf{- 1 0}$ & $\mathbf{- 1 5}$ & $\mathbf{- 2 5}$ & $\mathbf{- 2 8}$ & $\mathbf{- 2 8}$ \\
\hline
\end{tabular}

Table 3: Two-Day Responses of Swiss Government Bond Yields.

The table reports the two-day response of the six Swiss government bond yields used in model estimation around the SNB announcement dates. All numbers are measured in basis points.

\subsection{Empirical Term Structure Models}

In order to accurately decompose the two-day bond yield reactions, we need a term structure model that performs well at forecasting short-term policy interest rates. ${ }^{25}$ With such a forecast as a proxy for market expectations of future policy rates, we can then define and compute the term premium by rewriting equation (1):

$$
T P_{t}(\tau)=y_{t}(\tau)-\frac{1}{\tau} \int_{t}^{t+\tau} E_{t}^{P}\left[r_{s}\right] d s
$$

That is, the term premium is the difference in expected returns between a buy-and-hold strategy for a $\tau$-year Treasury bond and an instantaneous rollover strategy based on the risk-free rate $r_{t} .{ }^{26}$

We use the arbitrage-free Nelson-Siegel (AFNS) model class developed in Christensen et al. (2011, henceforth CDR). This model class has three state variables, $X_{t}=\left(L_{t}, S_{t}, C_{t}\right)$, that represent level, slope, and curvature components in the yield curve. Their dynamics are characterized by the following system of stochastic differential equations under the risk-

\footnotetext{
${ }^{25}$ Mirkov and Sutter (2013) and Söderlind (2010) are among the previous studies to analyze Swiss yields using Gaussian term structure models.

${ }^{26}$ Note that a Jensen's inequality term has been left out for the rollover strategy in this definition.
} 
neutral $Q$-measure used for pricing: ${ }^{27}$

$$
\left(\begin{array}{c}
d L_{t} \\
d S_{t} \\
d C_{t}
\end{array}\right)=\left(\begin{array}{ccc}
0 & 0 & 0 \\
0 & \lambda & -\lambda \\
0 & 0 & \lambda
\end{array}\right)\left[\left(\begin{array}{c}
\theta_{1}^{Q} \\
\theta_{2}^{Q} \\
\theta_{3}^{Q}
\end{array}\right)-\left(\begin{array}{c}
L_{t} \\
S_{t} \\
C_{t}
\end{array}\right)\right] d t+\Sigma\left(\begin{array}{c}
d W_{t}^{L, Q} \\
d W_{t}^{S, Q} \\
d W_{t}^{C, Q}
\end{array}\right), \quad \lambda>0 .
$$

In addition, the instantaneous risk-free rate is defined by

$$
r_{t}=L_{t}+S_{t}
$$

This specification implies that zero-coupon bond yields are given by

$$
y_{t}(\tau)=L_{t}+\left(\frac{1-e^{-\lambda \tau}}{\lambda \tau}\right) S_{t}+\left(\frac{1-e^{-\lambda \tau}}{\lambda \tau}-e^{-\lambda \tau}\right) C_{t}-\frac{A(\tau)}{\tau}
$$

where the factor loadings in the yield function match the level, slope, and curvature loadings introduced in Nelson and Siegel (1987). $A(\tau) / \tau$ is a yield-adjustment term, which captures convexity effects due to Jensen's inequality and ensures absence of arbitrage.

The model is completed with a risk premium specification that connects the $Q$-dynamics to the dynamics under the real-world $P$-measure. To facilitate empirical implementation, we use the essentially affine risk premium introduced in Duffee (2002). The factor dynamics of the maximally flexible specification of the AFNS model are then given by

$$
\left(\begin{array}{c}
d L_{t} \\
d S_{t} \\
d C_{t}
\end{array}\right)=\left(\begin{array}{ccc}
\kappa_{11}^{P} & \kappa_{12}^{P} & \kappa_{13}^{P} \\
\kappa_{21}^{P} & \kappa_{22}^{P} & \kappa_{23}^{P} \\
\kappa_{31}^{P} & \kappa_{32}^{P} & \kappa_{33}^{P}
\end{array}\right)\left[\left(\begin{array}{c}
\theta_{1}^{P} \\
\theta_{2}^{P} \\
\theta_{3}^{P}
\end{array}\right)-\left(\begin{array}{c}
L_{t} \\
S_{t} \\
C_{t}
\end{array}\right)\right] d t+\left(\begin{array}{ccc}
\sigma_{11} & 0 & 0 \\
\sigma_{21} & \sigma_{22} & 0 \\
\sigma_{31} & \sigma_{32} & \sigma_{33}
\end{array}\right)\left(\begin{array}{c}
d W_{t}^{L, P} \\
d W_{t}^{S, P} \\
d W_{t}^{C, P}
\end{array}\right) .
$$

We estimate this model for Swiss zero-coupon yields using a standard Kalman filter. Equation (3) is the measurement equation, while equation (4) is the transition equation in the Kalman filter; see CDR for technical details.

\subsection{Model Selection and Performance Evaluation}

We start out by using only the pre-crisis part of our sample, that is, the period from January 1998 to January 2008, to identify appropriate specifications of the AFNS model framework described above. This avoids the shocks and noise from the financial crisis. Furthermore, to ease the computational burden, these exercises are performed with data at weekly frequency,

\footnotetext{
${ }^{27}$ As per CDR, $\theta^{Q}$ is set to zero without loss of generality.
} 


\begin{tabular}{lccccc}
\hline \multirow{2}{*}{$\begin{array}{l}\text { Alternative } \\
\text { specifications }\end{array}$} & \multicolumn{5}{c}{ Goodness-of-fit statistics } \\
\cline { 2 - 6 } & $\log L$ & $k$ & $p$-value & AIC & BIC \\
\hline (1) Unrestricted $K^{P}$ & $19,463.57$ & 22 & n.a. & $-38,883.14$ & $-38,789.47$ \\
$(2) \kappa_{12}^{P}=0$ & $19,462.82$ & 21 & 0.2207 & $\mathbf{- 3 8 , 8 8 3 . 6 4}$ & $-38,794.23$ \\
$(3) \kappa_{12}^{P}=\kappa_{23}^{P}=0$ & $19,461.25$ & 20 & 0.0764 & $-38,882.50$ & $-38,797.35$ \\
$(4) \kappa_{12}^{P}=\kappa_{23}^{P}=\kappa_{21}^{P}=0$ & $19,460.20$ & 19 & 0.1473 & $-38,882.40$ & $-38,801.50$ \\
$(5) \kappa_{12}^{P}=\ldots=\kappa_{32}^{P}=0$ & $19,458.57$ & 18 & 0.0710 & $-38,881.14$ & $-38,804.50$ \\
$(6) \kappa_{12}^{P}=\ldots=\kappa_{13}^{P}=0$ & $19,456.32$ & 17 & 0.0339 & $-38,878.64$ & $\mathbf{- 3 8 , 8 0 6 . 2 6}$ \\
$(7) \kappa_{12}^{P}=\ldots=\kappa_{31}^{P}=0$ & $19,450.41$ & 16 & 0.0006 & $-38,868.82$ & $-38,800.70$ \\
\hline
\end{tabular}

Table 4: Evaluation of Alternative Specifications of the AFNS Model.

There are seven alternative estimated specifications of the AFNS model of Swiss government bond yields with the unrestricted 3-by-3 $K^{P}$ matrix being the most flexible. Each specification is listed with its maximum $\log$ likelihood value $(\log L)$, number of parameters $(k)$, the $p$-value from a likelihood ratio test of the hypothesis that it differs from the specification above with one more free parameter, and the information criteria (AIC and BIC). The sample is weekly from January 9, 1998, to January 4,2008 , a total of 522 observations.

unlike the daily data used in the real-time model estimations in the event study itself.

First, we build on the findings in CDR and limit the $\Sigma$ volatility matrix to be diagonal. To determine the appropriate specification of the mean-reversion matrix $K^{P}$, a general-to-specific modeling strategy is applied. Thus, after each estimation, we restrict the least significant parameter estimates to zero and then re-estimate the model. This strategy is continued down to the most parsimonious specification, which has a diagonal $K^{P}$ matrix. The final specification choice is based on the values of the Akaike and Bayesian information criteria as per Christensen et al. $(2010,2014)$ and CR. The summary statistics of the model selection process are reported in Table 4. The Akaike information criterion (AIC) is minimized by specification (2), while the Bayesian information criterion (BIC) is minimized by specification (6), that is,

$$
K_{A I C}^{P}=\left(\begin{array}{ccc}
\kappa_{11}^{P} & 0 & \kappa_{13}^{P} \\
\kappa_{21}^{P} & \kappa_{22}^{P} & \kappa_{23}^{P} \\
\kappa_{31}^{P} & \kappa_{32}^{P} & \kappa_{33}^{P}
\end{array}\right) \quad \text { and } \quad K_{B I C}^{P}=\left(\begin{array}{ccc}
\kappa_{11}^{P} & 0 & 0 \\
0 & \kappa_{22}^{P} & 0 \\
\kappa_{31}^{P} & 0 & \kappa_{33}^{P}
\end{array}\right)
$$

Due to the lack of any established benchmark model for Swiss government bond yields, we choose to compare the selected AFNS models to relevant alternative AFNS models. Specifically, we include the unconstrained AFNS model in equation (4), which is the AFNS model closest to the canonical $A_{0}(3)$ model of Dai and Singleton (2000), as well as the most parsimonious independent-factor AFNS model favored by CDR. Also, we consider the AFNS model 
with diagonal $\Sigma$ volatility matrix, but unrestricted $K^{P}$ mean-reversion matrix, which is the starting point for our model selection procedure, in addition to the specification favored by CR for US data with the $K^{P}$ matrix given by ${ }^{28}$

$$
K_{C R}^{P}=\left(\begin{array}{ccc}
\kappa_{11}^{P} & 0 & 0 \\
\kappa_{21}^{P} & \kappa_{22}^{P} & \kappa_{23}^{P} \\
0 & 0 & \kappa_{33}^{P}
\end{array}\right)
$$

We now re-estimate the specific AFNS models identified above on a weekly basis for the period after January 2008, adding one week of data at a time, in order to fully reflect the data available to market participants in real time during this period. We then forecast the three-month CHF LIBOR six months, one year, and two years ahead on a weekly basis over the period from January 4, 2008, until December 30, 2011, using the model-implied threemonth yield as a proxy for the three-month CHF LIBOR. As the three-month CHF LIBOR has been the target policy rate of the SNB since 1998, this exercise sheds light on the ability of the various AFNS models to project policy expectations. The summary statistics for the forecast errors relative to the subsequent realizations of the three-month CHF LIBOR are reported in Table 5, which also contains the forecast errors obtained using a random walk assumption. We note the strong forecast performance of the preferred AFNS model according to the BIC. In the remainder of the paper, we will refer to this specification as the preferred AFNS model. ${ }^{29}$

Table 6 contains the summary statistics for the fitted yield errors from this model. The fit is good, as indicated by the low fitted root mean-squared errors (RMSE), and almost without bias, on average, as the mean errors are very close to zero across the entire maturity range. We also test the significance of the parameter restrictions imposed on the $K^{P}$ meanreversion matrix in the preferred AFNS model relative to the corresponding AFNS model with an unrestricted $K^{P}$ matrix, using standard likelihood ratio tests. The results show that the parameter restrictions are supported by the data during our forecast period. Thus, the preferred AFNS model is flexible enough to capture the relevant information in the data throughout this period.

\footnotetext{
${ }^{28}$ This model nests the AFNS specification CR favored for UK gilt yields, which has the additional restriction $\kappa_{21}^{P}=0$. For this reason we do not include that model in the analysis.

${ }^{29}$ Unreported results for Diebold and Mariano (1995) tests of forecast accuracy show that the preferred AFNS model's short rate forecasts are statistically significantly more accurate than the random walk at all three forecast horizons. However, among the AFNS models, the preferred model's performance is not, in general, statistically superior to that of the other models.
} 


\begin{tabular}{|c|c|c|c|c|c|c|}
\hline \multirow{2}{*}{ Forecasting method } & \multicolumn{2}{|c|}{ Six-month forecast } & \multicolumn{2}{|c|}{ One-year forecast } & \multicolumn{2}{|c|}{ Two-year forecast } \\
\hline & Mean & RMSE & Mean & RMSE & Mean & RMSE \\
\hline Random walk & 33.55 & 79.33 & 62.37 & 113.65 & 71.26 & 123.57 \\
\hline Unconstrained AFNS model & -1.54 & 60.86 & 44.62 & 73.67 & 80.63 & 93.56 \\
\hline Unrestricted $K^{P}$ AFNS model & 22.28 & 63.40 & 72.80 & 85.43 & 110.27 & 116.27 \\
\hline Indep.-factor AFNS model & 11.80 & 60.18 & 51.96 & 72.89 & 78.46 & 90.14 \\
\hline CR AFNS model & 29.35 & 67.88 & 80.94 & 93.03 & 118.82 & 124.77 \\
\hline Preferred AIC AFNS model & 21.60 & 62.83 & 71.48 & 83.23 & 107.97 & 113.27 \\
\hline Preferred BIC AFNS model & 13.82 & 61.00 & 54.31 & 73.97 & 80.22 & 91.15 \\
\hline
\end{tabular}

Table 5: Summary Statistics for Policy Target Rate Forecast Errors.

Summary statistics of the forecast errors - mean and root mean-squared errors (RMSEs) - of the threemonth CHF LIBOR six months, one year, and two years ahead. The forecasts are weekly starting on January 4, 2008, and running until December 30, 2011, a total of 209 forecasts for all three forecast horizons. All measurements are expressed in basis points.

\begin{tabular}{cccc}
\hline Maturity & \multicolumn{3}{c}{ Preferred AFNS model } \\
\cline { 2 - 4 } in months & Mean & RMSE & $\widehat{\sigma}_{\varepsilon}\left(\tau_{i}\right)$ \\
\hline 12 & -4.78 & 13.51 & 13.64 \\
24 & -0.12 & 1.20 & 1.96 \\
36 & 0.55 & 2.04 & 2.29 \\
60 & 0.06 & 0.60 & 0.92 \\
84 & -0.39 & 1.14 & 1.44 \\
120 & 0.00 & 0.00 & 2.24 \\
\hline
\end{tabular}

Table 6: Summary Statistics of Fitted Errors.

The mean and root mean-squared fitted errors of the Swiss government bond yields across six different maturities are shown. Also reported are the estimated measurement error standard deviations for each maturity. All numbers are measured in basis points. The data are weekly covering the period from January 9, 1998, to January 4, 2008.

\subsection{Decomposition of the Yield Responses to the SNB Announcements}

We now use the empirical term structure models to assess the different channels of transmission of the SNB announcements to Swiss long-term yields. We decompose Swiss zero-coupon yields into three components: ${ }^{30}$

(i) the estimated average expected short rate until maturity;

(ii) the term premium defined as the difference between the model fitted yield and the average expected short rate; and

(iii) a residual that reflects variation not accounted for by the model.

Figure 6 shows the result of the decomposition of ten-year Swiss government bond yields since 2008 (excluding the residual, which is sufficiently small to be irrelevant). Over the

\footnotetext{
${ }^{30}$ Appendix B provides the analytical formulas required for the decomposition in the preferred AFNS model.
} 


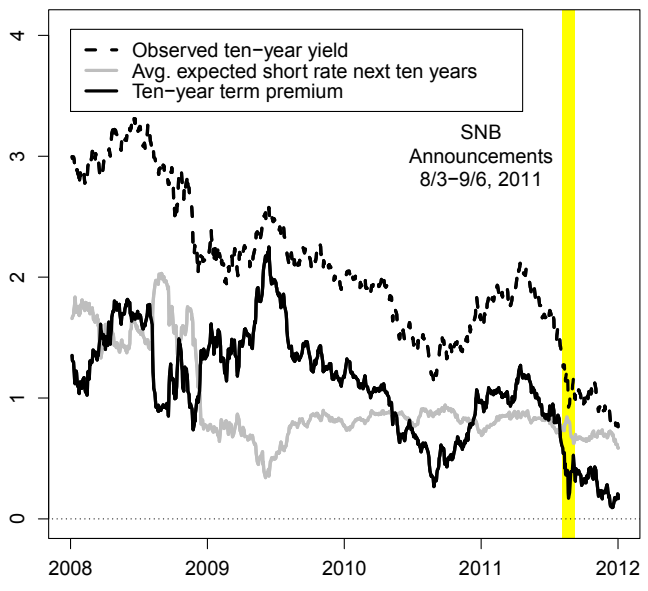

(a) 2008-2011.

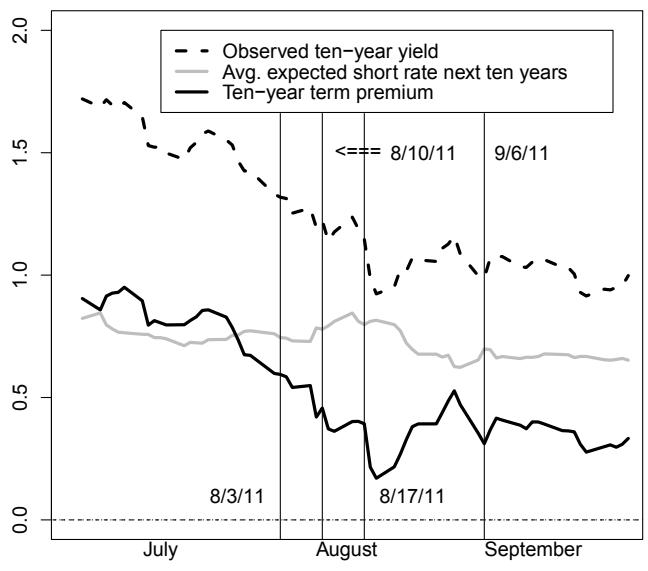

(b) Summer of 2011.

Figure 6: Decomposition of Ten-Year Yield.

Panel (a) shows the daily real-time decomposition of the variation of the ten-year Swiss government bond yield into (i) estimated average expected short rate forecasted until maturity and (ii) the term premium defined as the difference between the observed government bond yield and the average expected short rate based on the preferred AFNS model of Swiss government bond yields. Panel (b) shows the daily movements around the four 2011 SNB unconventional policy announcements, indicated with solid black vertical lines. The data are daily covering the period from January 3, 2008, to December 30, 2011.

period from August 1, 2011, to the date of the introduction of the exchange rate floor on September 6, 2011, the observed ten-year government bond yield declined 35 basis points. According to our preferred AFNS model, policy expectations as reflected in the estimated average expected short rate over the next ten years only declined four basis points, while the ten-year term premium accounts for 31 of the 35 basis point yield decline, or 89 percent. However, the key question is to what extent the announced reserve expansions by the SNB are the driver of these yield changes. This would be more likely if they take place in the immediate aftermath of the announcements. With the yield decomposition in hand, we hence resume the event analysis. We use our AFNS models, now estimated in real time at daily frequency, to decompose the response of the Swiss government bond yield to the SNB announcements into the three components described above.

Table 7 contains the results of decomposing the two-day ten-year yield responses based on the empirical AFNS models. ${ }^{31}$ Despite the differences in statistical fit and forecast performance documented earlier, the models agree on what drove yield changes on the announcement dates. Three of the four models, including our preferred specification, indicate that

\footnotetext{
${ }^{31}$ The one-day response decompositions are reported in Appendix C.
} 


\begin{tabular}{|c|c|c|c|c|c|}
\hline \multirow[b]{2}{*}{ Event } & \multirow[b]{2}{*}{ Model } & \multicolumn{3}{|c|}{ Decomposition from models } & \multirow[b]{2}{*}{$\begin{array}{c}\text { Ten-year } \\
\text { yield }\end{array}$} \\
\hline & & $\begin{array}{l}\text { Avg. target rate } \\
\text { next ten years }\end{array}$ & $\begin{array}{c}\text { Ten-year } \\
\text { term premium }\end{array}$ & Residual & \\
\hline \multirow{4}{*}{ I Aug. 3, 2011} & Unconstrained AFNS & -5 & 2 & 1 & \multirow{4}{*}{-2} \\
\hline & Unrestricted $K^{P}$ AFNS & -2 & -1 & 1 & \\
\hline & Indep.-factor AFNS & -3 & -1 & 1 & \\
\hline & Preferred AFNS & -2 & -1 & 1 & \\
\hline \multirow{4}{*}{ II Aug. 10, 2011} & Unconstrained AFNS & -3 & -2 & -1 & \multirow{4}{*}{-6} \\
\hline & Unrestricted $K^{P}$ AFNS & 0 & -4 & -1 & \\
\hline & Indep.-factor AFNS & 1 & -5 & -1 & \\
\hline & Preferred AFNS & 1 & -5 & -1 & \\
\hline \multirow{4}{*}{ III Aug. 17, 2011} & Unconstrained AFNS & 0 & -20 & 0 & \multirow{4}{*}{-20} \\
\hline & Unrestricted $K^{P}$ AFNS & 4 & -23 & -2 & \\
\hline & Indep.-factor AFNS & -1 & -17 & -2 & \\
\hline & Preferred AFNS & $\mathbf{0}$ & -19 & -2 & \\
\hline \multirow{4}{*}{ Total net change } & Unconstrained AFNS & -8 & -19 & 0 & \multirow{4}{*}{-28} \\
\hline & Unrestricted $K^{P}$ AFNS & 2 & -28 & -2 & \\
\hline & Indep.-factor AFNS & -3 & -23 & -2 & \\
\hline & Preferred AFNS & -1 & -25 & -2 & \\
\hline
\end{tabular}

Table 7: Decompositions of Two-Day Responses of Ten-Year Yield.

The decomposition of two-day responses of the ten-year Swiss government bond yield on three SNB announcement dates into changes in (i) the average expected target rate over the next ten years, (ii) the ten-year term premium, and (iii) the unexplained residual based on empirical AFNS models of Swiss government bond yields. All changes are measured in basis points.

policy expectations were only marginally revised lower in response to the announcements, so that most of the yield declines are associated with declines in term premiums. ${ }^{32}$

The largest drop in the term premium, as well as the total yield, follows the third and largest announced reserve expansion. While we cannot directly identify the causes of this, we note that it may be related to the size of the expansion, or to possible nonlinearities in banks' portfolio response to reserve expansions.

All four models indicate that short rate expectations declined moderately around the first announcement on August 3, 2011, when the top of the target range for the three-month CHF LIBOR was lowered. This is the only evidence of any notable signaling effect that we detect in our analysis. ${ }^{33}$

These relatively small signaling effects are in contrast to the general perception at the time that the strong reaction of short money market rates to the announcements was a form

\footnotetext{
${ }^{32}$ We note that these results are not sensitive to the maturity considered. In Appendix D, we report qualitatively similar results for model decompositions of the five-year yield response.

${ }^{33}$ For robustness, we repeated the analysis using a novel class of shadow-rate AFNS models introduced in Christensen and Rudebusch (2015) that respects the zero lower bound for yields. The results are reported in Appendix $\mathrm{F}$ and indicate a greater share of signaling effects for all three announcements. However, it remains the case that the yield response to the third and most forceful announcement is decomposed as being driven predominantly by a decline in the term premium.
} 
of a signaling effect. In Appendix A, we reconcile these perceptions with our model results by taking an in-depth look at Swiss money market rates around the August 2011 announcements.

To summarize, we find that the drops in Swiss long-term government bond yields following the three announcements mainly reflected declines in the term premium, which is suggestive of reserve-induced portfolio balance effects.

Still, changes in term premiums could reflect other factors as well, not least because the episode took place during a turbulent phase of the European sovereign debt crisis. We address this next.

\section{Robustness}

In this section, we show that the SNB announcements of reserve expansions, particularly the third and most forceful announcement, remain the most likely direct cause for the identified declines in Swiss term premiums when controlling for other potential drivers.

We show this using regressions in first differences with announcement dummies in which we control for the effects of changes in foreign term premiums, Swiss government bond market liquidity, and financial market certainty. Furthermore, we consider whether other events happened during the announcement windows that could have moved the Swiss term premium. Finally, in the absence of intraday data on Swiss Confederation bond yields, we investigate the dynamics of the intraday responses to the announcements using Swiss ten-year interest swap rates.

\subsection{Controlling for Foreign Developments, Liquidity, and Uncertainty}

The SNB policy announcements in August 2011 came at a time of substantial market upheaval, high volatility, and flights to safety. This was an intense part of the European sovereign debt crisis. Elevated risk perceptions and developments abroad could have induced a fall in term premiums in the wake of the SNB's announcements of reserve expansions. We first want to control for movements in foreign term premiums as a driver of the declines in Swiss term premiums following the SNB announcements. To that end, we focus on movements in the US and euro-area government bond markets, widely regarded as the two most liquid fixed-income markets in the world.

For the estimation of US term premiums, we choose to rely on the shadow-rate model 
analyzed in Christensen and Rudebusch (2013). ${ }^{34,35}$ The shadow-rate modeling approach allows us to preserve the Gaussian factor dynamics, while we obtain bond yields that respect the zero lower bound. This aspect matters for modeling US Treasury yields in the most recent period..$^{36}$

We use German government bond yields as a substitute for the unobserved euro-area-wide default risk-free yield curve. ${ }^{37}$ Without an established euro-area benchmark term structure model, we went through a model selection analysis similar to the one described for Swiss yields based on the German government bond yields. The resulting preferred AFNS model for German yields has $P$-dynamics given by ${ }^{38}$

$$
\left(\begin{array}{c}
d L_{t} \\
d S_{t} \\
d C_{t}
\end{array}\right)=\left(\begin{array}{ccc}
10^{-7} & 0 & 0 \\
0 & \kappa_{22}^{P} & \kappa_{23}^{P} \\
0 & 0 & \kappa_{33}^{P}
\end{array}\right)\left[\left(\begin{array}{c}
0 \\
\theta_{2}^{P} \\
\theta_{3}^{P}
\end{array}\right)-\left(\begin{array}{c}
L_{t} \\
S_{t} \\
C_{t}
\end{array}\right)\right] d t+\left(\begin{array}{ccc}
\sigma_{11} & 0 & 0 \\
0 & \sigma_{22} & 0 \\
0 & 0 & \sigma_{33}
\end{array}\right)\left(\begin{array}{c}
d W_{t}^{L, P} \\
d W_{t}^{S, P} \\
d W_{t}^{C, P}
\end{array}\right) .
$$

This is identical to the AFNS specification CR favored for their analysis of UK gilt yield responses to the announcements by the Bank of England regarding its QE programs.

Figure 7 shows the ten-year term premium from our preferred AFNS model for Swiss yields and compares it to the estimates of the corresponding foreign term premiums. It shows that following the third announcement, the US term premium fell by six basis points in the event window (see the decompositions of foreign term premiums in Appendix E). The US term premium is more volatile than the Swiss term premium, and in contrast to the Swiss drop following the third announcement, this daily change of six basis points in the US term premium is not unusual. The correlation of changes in the Swiss and euro-area ten-year term premiums and the Swiss and US ten-year term premiums are 17.5 percent and 35.9 percent, respectively, over the period from January 4, 2010, to July 29, 2011. This underscores the importance of controlling for foreign developments, and for US term premium movements in particular, in our assessment.

Since part of the term premium could be a premium investors require for assuming the

\footnotetext{
${ }^{34}$ Since Christensen and Rudebusch (2013) only consider weekly data, we estimate their shadow-rate model on an updated sample of the daily Treasury yields used in CR.

${ }^{35}$ See Christensen et al. (2015) for additional applications of this shadow-rate model.

${ }^{36} \mathrm{It}$ is not obvious that we would want to enforce a lower yield bound for either the Swiss or the German bond yields also analyzed, mainly because in both of these samples yields have actually been well below zero for intermediate maturities for extended periods in recent years. Hence, in these cases, a standard Gaussian modeling approach appears to be fully warranted.

${ }^{37}$ The data are available on the website of the German Bundesbank: http://www.bundesbank.de/Navigation /EN/Statistics/Time_series_databases/Macro_economic_time_series/macro_economic_time_series_node.html.

${ }^{38}$ The results leading to this conclusion are available from the authors upon request.
} 


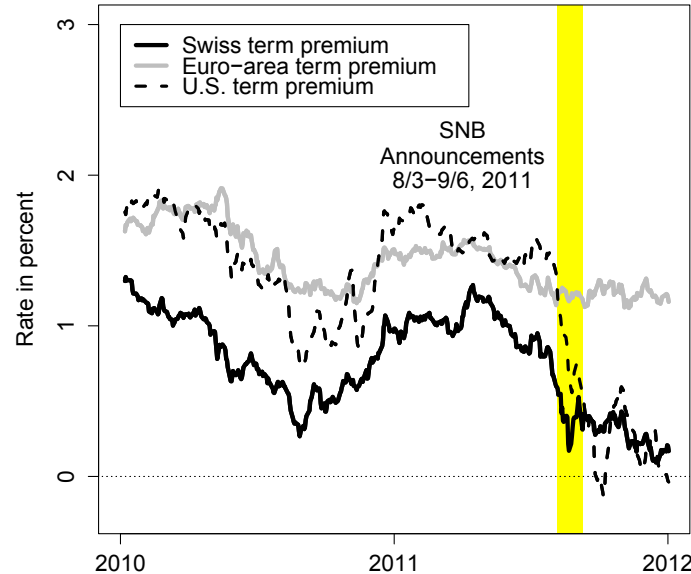

(a) $2010-2011$.

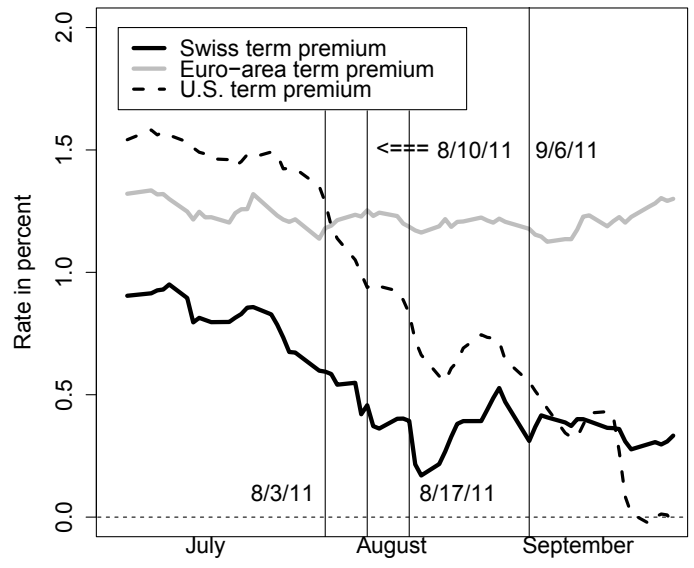

(b) Summer of 2011 .

Figure 7: Swiss and Foreign Ten-Year Term Premiums.

Panel (a) shows the daily Swiss, euro-area, and US ten-year term premiums. Panel (b) shows the daily movements around the four 2011 SNB unconventional policy announcements, indicated with solid black vertical lines. The data cover the period from January 4, 2010, to December 30, 2011. The source of each is detailed in the main text.

liquidity risk of Swiss Confederation bonds, we also want to control for changes in liquidity. To capture variation in the liquidity of the Swiss Confederation bond market, we use the average bid-ask spread of all available Confederation bonds weighted by the outstanding notional value of each bond. ${ }^{39,40}$ For the period from January 4, 2008, to August 2, 2011, that is, until the day before the first SNB announcement, the correlation between the term premium and the smoothed bid-ask spread was 43.3 percent. This suggests a positive connection between the two series. Thus, both on economic and statistical grounds, we want to control for the impact of this measure of market liquidity.

Our final control variable is a measure of priced economic uncertainty, namely the VIX options-implied volatility index. It represents near-term uncertainty about the general stock market as reflected in one-month options on the Standard and Poor's 500 stock price index and is widely used as a gauge of investor fear and risk aversion. When the price of uncertainty goes up as reflected in higher values of the VIX, risk premiums tend to go up. However, in the case of Switzerland during the European sovereign debt crisis, spikes in the VIX could also be a trigger for safe-haven demand for Swiss assets. Thus, the role of the VIX for Swiss term premiums is not clear beforehand, but like the other measures we want to control for

\footnotetext{
${ }^{39}$ The data are based on SNB staff's own calculations. The sample made available to us runs from April 3, 2000, to December 12, 2011.

${ }^{40}$ Fleming (2003) finds that bid-ask spreads are a useful measure of liquidity in the US Treasury bond market.
} 
changes in market uncertainty in our analysis.

To control for foreign and financial market developments, we run a simple ordinary least squares regression in first differences of the Swiss term premium on the German and US term premiums, the bid-ask spread, and the VIX. The foreign term premiums and the VIX are lagged by one day, because these data are recorded at market close, whereas the Swiss data are recorded in the morning. We further include dummies for the three events, also lagged, to capture the residual reaction in the Swiss term premium between the morning of the announcement and the morning of the day after the announcement. ${ }^{41}$

For the purposes of this regression we make the simplifying assumption that the Swiss policy announcements had a minimal, if any, effect on foreign financial variables. This allows us to treat foreign term premiums and the VIX as purely exogenous variables. While this assumption is necessary for establishing causality, Swiss announcements may in fact have affected foreign financial market developments. The announcements were unprecedented and were commented on in the international press. By treating foreign variables as exogenous, we may therefore be underestimating the effects of the three announcements.

The regression results are reported in Table 8 for the ten-year term premium. ${ }^{42}$ The coefficient for the US term premium is positive and highly statistically significant, while the euro-area term premium has a positive and highly statistically significant coefficient by itself (not shown) but becomes insignificant once combined with the US term premium. The bid-ask spread is also significant by itself (also not shown) but insignificant when combined with the VIX, suggesting at most a weak link between the term premium and measures of market liquidity. The VIX is highly statistically significant throughout, and with a negative coefficient, which indicates that periods of uncertainty tend to coincide with declines in Swiss term premiums. We interpret this as evidence of a flight-to-safety effect in Swiss bond markets.

Most importantly, the coefficients on the three event dummies confirm the findings of the event study in Section 4.5. Without the controls (column 1 in Table 8), all three events are significant and suggest that Swiss term premiums fell in response to these announcements. The orders of magnitude are very close to those identified in Section 4.5. When controlling for foreign term premiums (column 2 in Table 8), the first event dummy turns insignificant. Column 4 shows the regression including all control variables. This is the specification with the highest adjusted $R^{2}$. The second and third events remain highly significant despite the

\footnotetext{
${ }^{41}$ The regressions are run in one-day differences rather than two-day differences to preclude econometric complications due to moving averages in the dependent variable. We additionally ran regressions on two-day differences to match our event window, but the results were the same, and hence not reported.

${ }^{42}$ Table 13 in Appendix D reports the corresponding regression results for the five-year term premium.
} 


\begin{tabular}{|c|c|c|c|c|}
\hline \multirow{2}{*}{ Explanatory variables } & \multicolumn{4}{|c|}{ First differences } \\
\hline & $(1)$ & $(2)$ & $(3)$ & $(4)$ \\
\hline DUM 3 Aug 2011 & $\begin{array}{c}-0.7826^{* *} \\
(0.1689)\end{array}$ & $\begin{array}{c}0.5114 \\
(0.4288)\end{array}$ & $\begin{array}{c}-0.9877^{* *} \\
(0.3427)\end{array}$ & $\begin{array}{c}0.1984 \\
(0.5912)\end{array}$ \\
\hline DUM 10 Aug 2011 & $\begin{array}{c}-8.3490^{* *} \\
(0.1689)\end{array}$ & $\begin{array}{c}-5.9209^{* *} \\
(0.4883)\end{array}$ & $\begin{array}{c}-5.3469^{* *} \\
(0.7112)\end{array}$ & $\begin{array}{c}-4.0834^{* *} \\
(0.7266)\end{array}$ \\
\hline DUM 17 Aug 2011 & $\begin{array}{c}-17.5819^{* *} \\
(0.1689)\end{array}$ & $\begin{array}{c}-15.9377^{* *} \\
(0.2546)\end{array}$ & $\begin{array}{c}-17.3549^{* *} \\
(0.6060)\end{array}$ & $\begin{array}{c}-16.0428^{* *} \\
(0.6949)\end{array}$ \\
\hline Euro-area term premium & & $\begin{array}{c}0.0559 \\
(0.0571)\end{array}$ & & $\begin{array}{c}0.0302 \\
(0.0580)\end{array}$ \\
\hline US term premium & & $\begin{array}{c}0.2045^{* *} \\
(0.0308)\end{array}$ & & $\begin{array}{c}0.1666^{* *} \\
(0.0325)\end{array}$ \\
\hline Bid-ask spread & & & $\begin{array}{l}-2.2160 \\
(1.7183)\end{array}$ & $\begin{array}{l}-1.8633 \\
(1.8672)\end{array}$ \\
\hline VIX & & & $\begin{array}{c}-0.3988^{* *} \\
(0.0865)\end{array}$ & $\begin{array}{c}-0.3022^{* *} \\
(0.0936)\end{array}$ \\
\hline Adjusted $R^{2}$ & 0.07 & 0.17 & 0.16 & 0.22 \\
\hline
\end{tabular}

Table 8: First Difference Regressions of the Swiss Ten-Year Term Premium.

The table shows the results of regressing the daily changes in the ten-year Swiss term premium from the preferred AFNS model on the matching (in time) daily changes in German and US term premiums as described in the main text, in addition to the changes in the bid-ask spread in the Confederation bond market and the VIX. A constant is included in all regressions, but never significant and not shown. The sample is daily from January 4, 2010, to December 12, 2011, a total of 479 observations. Newey-West serial correlation corrected standard errors based on a lag length of five are reported in parentheses. Asterisks ${ }^{*}$ and ${ }^{* *}$ indicate significance at the 5 percent and 1 percent levels, respectively.

controls. The size of the second event dummy is reduced from -8.3 basis points to -4.1 basis points when all controls are included, suggesting that about half of the fall in the term premium that day can be explained by factors other than the SNB announcement (assuming the control variables were indeed exogenous to the Swiss announcement). The remaining announcement effect continues to be highly significant, however. Moreover, the third event is highly significant, and its magnitude remains largely unchanged around -17 basis points across all specifications.

We conclude that the substantial drop in the Swiss term premium following the third announcement was not driven by foreign or market developments, but indeed is likely to have been a result of the forceful SNB announcement that morning. 


\subsection{Other Events}

As another robustness check, we investigate whether other major news events occurring around the time of the SNB announcements could potentially explain our findings. Appendix $\mathrm{G}$ provides a log of the most notable economic events in August and September 2011. The first important event that comes to mind is the FOMC meeting on August 9, 2011, when US monetary policymakers introduced explicit monetary policy forward guidance for the first time. Even though this event may corrupt the Swiss financial market response to the second SNB announcement on August 10, 2011, we note that this is not the dominating event on either the Swiss or foreign side in our controlling exercises. Thus, our conclusion is unlikely to be biased to any notable extent by this particular event.

We did not find any other important events that could have been driving financial markets in the event window following the announcement on August 17, 2011. European financial markets were relatively calm that day. This changed the following day with an event that was symptomatic for the general state of stress relating to the European sovereign debt crisis in the fall of 2011. On August 18, 2011, rumors circulated that the ECB's US dollar facility was tapped by a European bank, signaling funding stress. This triggered a bank equity selloff. Between market close on August 17, 2011, and August 18, 2011, European stock prices (bank stock prices in particular) plunged and volatility measures rose sharply, suggesting a strong flight to safety. Importantly, though, this flight to safety in European equity markets did not overlap in time with the drop in the Swiss term premium on August 17, 2011.

\subsection{Intraday Evidence}

Unfortunately, we do not have access to intraday prices for Swiss Confederation bonds that could help us shed light on the exact timing of the market reaction to the three SNB announcements. Instead, we look at a close substitute for Confederation bonds for which we do have intraday data, namely quoted rates on Swiss ten-year interest rate swap contracts.

Figure 8 shows the intraday variation of the Swiss ten-year interest swap rate on the day before and the day of the three SNB announcements. First, we note that there is little overall variation on the day before each SNB announcement. It hence does not appear as if there is anything material going on in the run-up to any of the three SNB announcements. Second, the market reaction differs across the three announcements. In Figure 8(b), we see evidence of the signaling effect around the first announcement as the ten-year swap rate drops immediately following the announcement. In contrast, Figures $8(\mathrm{~d})$ and $8(\mathrm{f})$ indicate that the responses 


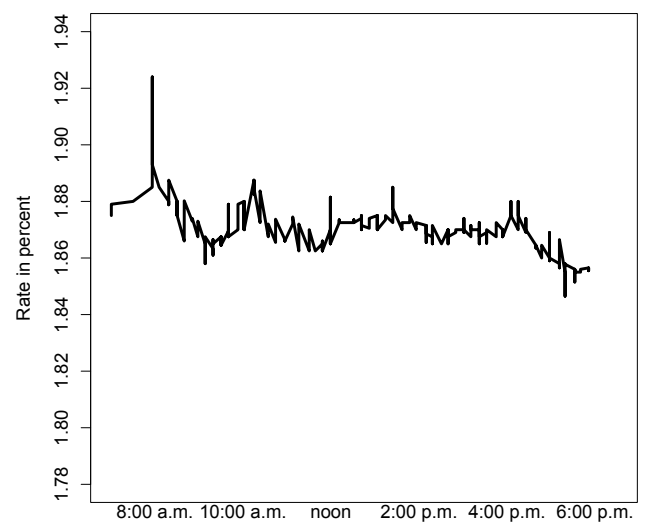

(a) August 2, 2011.

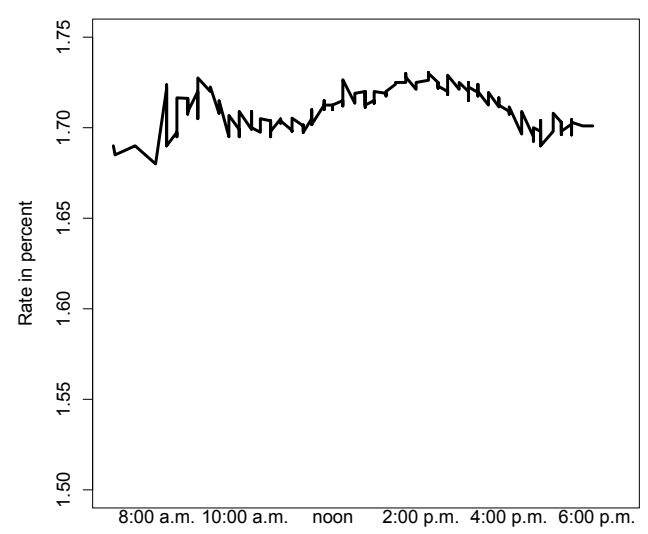

(c) August 9, 2011.

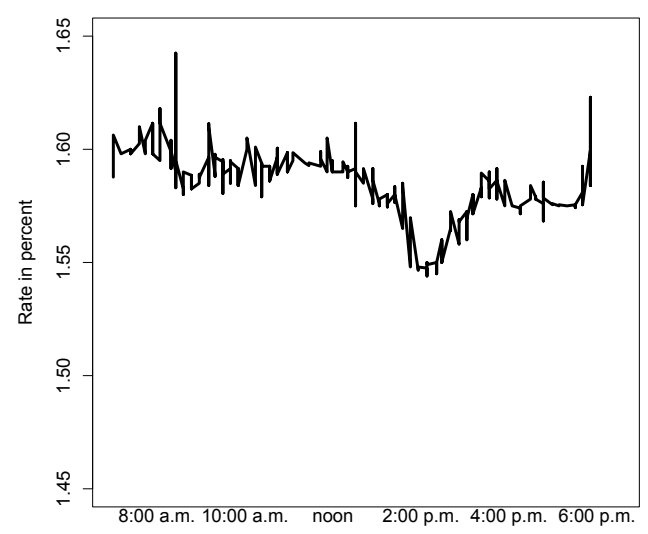

(e) August 16, 2011.

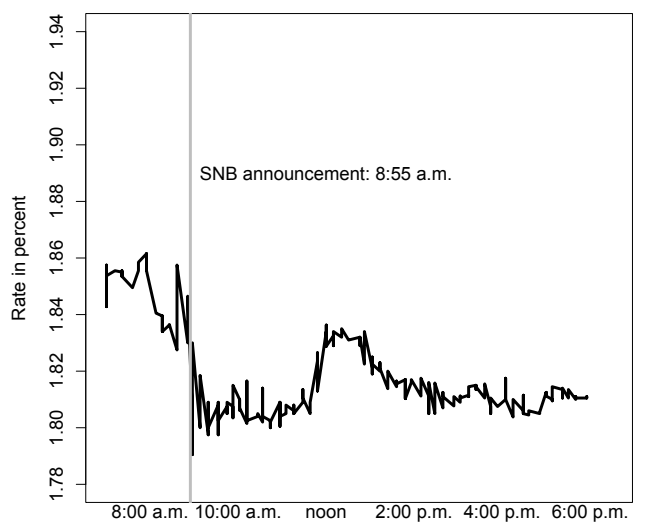

(b) August 3, 2011.

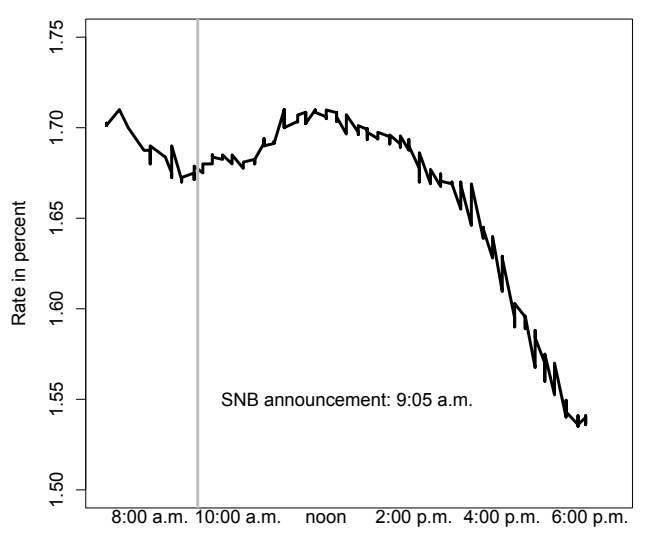

(d) August 10, 2011.

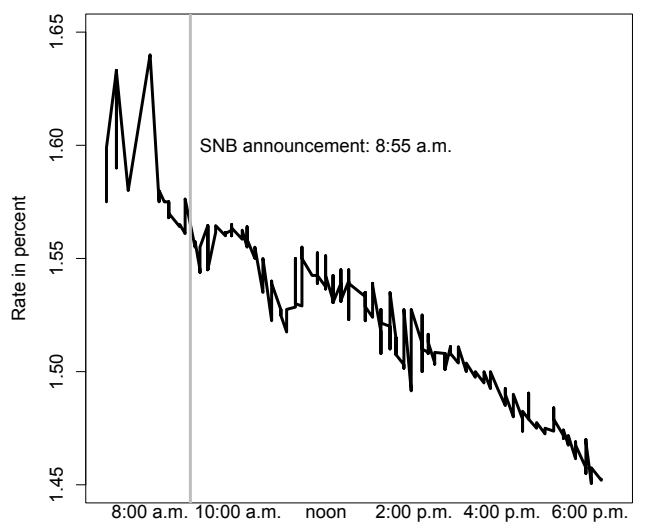

(f) August 17, 2011.

Figure 8: Intraday Movement of the Swiss Ten-Year Interest Swap Rate.

Intraday variation in the Swiss ten-year interest swap rate on the day before and the day of the three SNB announcements. Source: Bloomberg. 
to the last two announcements were rather gradual, and do not suggest that investors took much of a signal about future policy rates from those measures - again consistent with our model decompositions. In contrast, the market reactions follow a pattern of gradual yield declines throughout the remainder of the announcement day. We interpret this as evidence that it took some time for investors to digest and assess the impact on risk premiums from the extraordinary measures. This also supports the use of two-day event windows. Overall, the intraday evidence appears to be consistent with the findings from the daily data.

\section{Conclusion}

In the rapidly growing literature on the effects of QE on financial markets, two channels have received the most attention, namely the signaling channel and the portfolio balance effect of changes in the market supply of the purchased assets. In this paper, we emphasize that another source of portfolio balance effects may be important, notably the portfolio reallocation effect arising from the expansion of excess reserves that is a defining part of any QE program.

To obtain evidence on the latter channel, we study the unconventional monetary policy measures undertaken by the SNB in the late summer of 2011, prior to introducing the minimum exchange rate in early September 2011. The design of these policies provides a unique case study for identifying reserve-induced portfolio balance effects on long-term interest rates. The reason is that, in contrast to the QE programs conducted in the United Kingdom and the United States, the SNB policy measures involved an unprecedented expansion of excess reserves without any outright purchases of domestic long-term securities. Thus, this represents a pure QE program in the terminology of Bernanke and Reinhart (2004).

Long-term Swiss Confederation bond yields dropped by a cumulative total of 28 basis points, or one-fifth of the yield, following the three SNB announcements of reserve injections. To understand the transmission channels through which the expansion of reserves affected long-term yields, we apply standard event study techniques and the estimation of dynamic term structure models to data on Swiss Confederation bond yields. The modeling approach allows us to decompose the observed yield changes into a component that represents expectations of future short policy rates and a residual term premium component. We find that the main part of the drop in yields in response to the SNB announcements reflect declines in term premiums. Only the first announcement on August 3, 2011, which included a lowering of the upper bound for the three-month CHF LIBOR, is associated with any notable signaling effect. These findings are robust across model specifications. 
To the best of our knowledge, this paper is the first to document that part of the transmission channel of $\mathrm{QE}$ programs to long-term interest rates may derive from a portfolio balance effect through the expansion of reserves.

While 28 basis points may seem modest in comparison to an expansion of reserves on the order of $30 \%$ of GDP, we note that the yield drop should be seen in relation to the part of the reserve expansions that resulted from open market operations with non-bank counterparties as explained in Section 2.2. Unfortunately, we do not have access to conclusive data on the ratio of non-bank to bank counterparties for the Swiss expansions in August 2011. The ratio is likely to have depended on the types of transactions, and we speculate that, by the nature of assets acquired by the SNB, it may have been moderate on average across transactions. These observations suggest that a better understanding of asset market structures and the preferences of different types of market participants could contribute to more accurate assessments of the channels of transmission of QE and their effectiveness.

Have such reserve-induced portfolio balance effects been empirically relevant as drivers of long-term interest rates in connection with the major QE programs in the US and the UK? Since these programs consisted of long-term bond purchases, both supply- and reserveinduced portfolio balance effects may have been present and cannot be separately identified empirically because they impact long-term bond yields simultaneously.

We do think, however, that the circumstances surrounding these programs make the existence of some reserve-induced effects likely. Carpenter et al. (2013) conclude that the ultimate sellers of assets to the Federal Reserve in connection with its QE programs were non-banks. Moreover, Ennis (2014) illustrates how US banks now hold a substantially larger amount — around 50 percent - of their securities and liquid asset portfolio in reserves compared to the years before the crisis (see also Ennis and Wolman, 2015). The UK asset purchase program was, at least initially, conducted explicitly in assets held by non-bank financial institutions with the intention of boosting broader monetary aggregates according to Joyce et al. (2011). This suggests that reserve effects could be of practical relevance for understanding the transmission of these QE programs.

Whether or not our findings extend to other countries is an important question, and one that warrants more research. The presence of a bank portfolio balance effect resulting from QE through an expansion of reserves has implications for the design of future QE programs, for the exit from such programs, and for central bank communication. 


\section{Appendix A: Reaction of Swiss Money Markets in August 2011}

In this appendix, we describe and analyze the reaction of Swiss money markets to the three SNB announcements in August 2011.

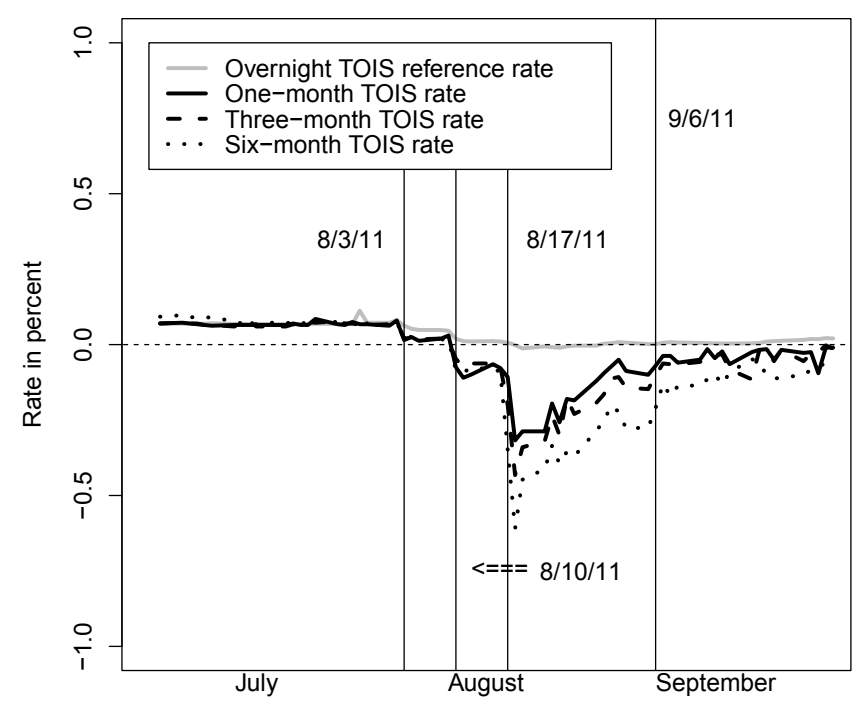

Figure 9: Swiss TOIS Rates.

Illustration of the movements in the overnight TOIS reference rate and the one-, three-, and six-month TOIS rates around the four SNB unconventional policy announcements shown with solid black vertical lines. Source: SNB.

To begin, Figure 9 plots the development in selected short-maturity Swiss franc term overnight indexed swap (TOIS) rates. Changes in TOIS rates are usually taken as good proxies for changes in expected future short-term interest rates. ${ }^{43}$ The depicted rates dropped by 30 to 70 basis points and turned negative in the weeks following the first announcement. The strongest reaction came after the third announcement, when the three-month TOIS rate fell 17 basis points to -0.24 percent within a few hours of the announcement and a further 22 basis points on the following day, reaching its lowest point ever of -0.46 percent. To put this reaction into perspective, a change of 22 basis points in the three-month TOIS rate amounts to seven standard deviations of its daily variation since records began in 2000. The SNB's intermediate aim of pushing down money market rates through reserve expansions clearly was very successful.

A negative three-month TOIS rate means that the counterparty paying the floating rate is willing to pay a fixed rate (for example 0.46 percent) for a three-month period for the right to also pay the floating overnight rate to the counterparty. This only makes sense if there is a possibility that the overnight rate could turn

\footnotetext{
${ }^{43}$ TOIS quotes are collected around 11 a.m. on each business day. We would ideally want to investigate long-term Swiss franc TOIS rates, which would reflect the expected policy path over a longer horizon. However, traded TOIS contracts with long maturities are few and the market for such contracts developed only recently and is not liquid. For this reason, we consider TOIS rates of the more liquid part of the market with maturities up to six months.
} 


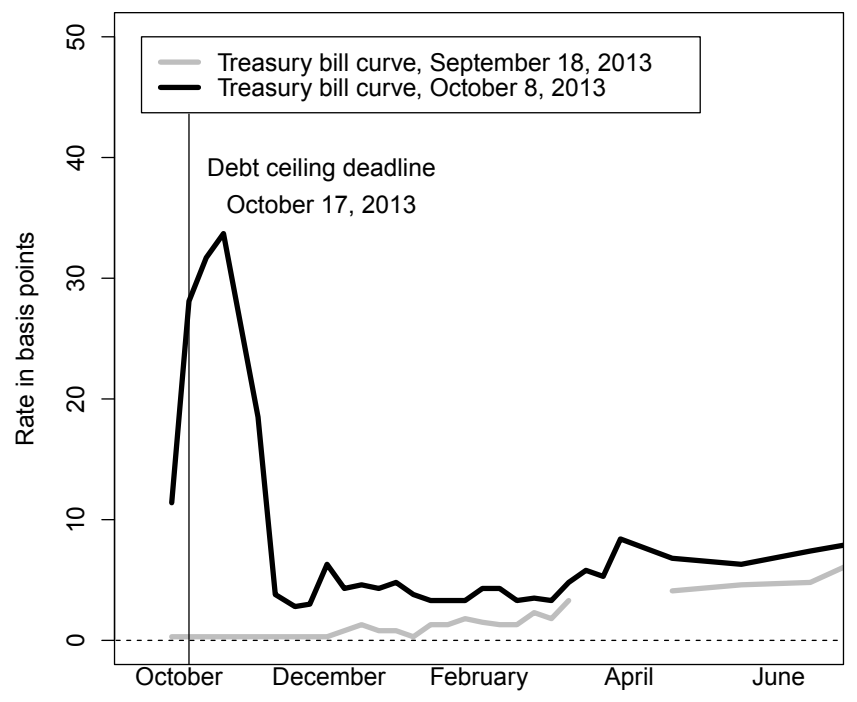

Figure 10: U.S. Treasury Bill Curve ahead of the US Debt Ceiling Deadline.

Illustration of the US Treasury bill curve on October 8, 2013, a few days before the official debt ceiling for the US federal government would be breached. For comparison the Treasury bill curve on September 18, 2013, is shown. Source: Bloomberg.

negative during the next three months. As already discussed, the financial press at the time indeed speculated that the SNB might introduce negative interest rates. It is therefore likely that investors placed a much higher probability on the SNB introducing negative interest rates after having observed that the SNB was prepared to take steps like those announced in August 2011.

We consider these strong dips into negative territory to represent a short-term expectation, that is, market participants may have increased the probability they attached to the SNB imposing negative interest rates, but if negative interest rates were imposed, they did not expect those rates to stay negative for long. We hence do not consider the drops in rates to imply signaling effects for long-term yields. Our reasons for this interpretation are provided in the following.

First, market participants were expecting the SNB to take crisis measures, rather than seek to loosen the overall monetary policy stance. A crisis measure such as negative interest rates, if effective, should only affect expected short rates in the very near term (during the crisis), making any effect on longer-term interest rates very small. One parallel would be the market reaction around the approaching debt ceiling deadline for the US federal government in October 2013. Unlike the Swiss case, where we can only speculate about what type of scenarios investors were fearing, the US debt ceiling episode presented a tangible risk of default at a specific, known time. This makes it useful for drawing comparisons. Figure 10 shows yields on outstanding US Treasury bills on two days, one several weeks before the official deadline and the other just days before it. Bills that would mature immediately after the debt ceiling deadline were seriously affected, while bills with maturities further in the future barely responded. Apparently, investors expected that, even if a technical default were to happen, it would be short-lived - measures would be taken to solve the problem. The key takeaway is that rather extreme 
priced expectations for near-term events can exist with no material implications for medium- and long-term expectations. We suspect that the Swiss money market reaction following the SNB announcements in August 2011 is an example of this case.

Second, the rapid reversal in the rates after August 17, 2011, implies that the net decline from the end of July 2011 through September 2011 is much smaller and more consistent with the variation observed in the Swiss Confederation bond market that our empirical model-based analysis in Section 4 relies upon.

Third, changes in expected future short rates are not confirmed by the monthly Consensus Forecasts survey of professional forecasters. This survey suggests that the biggest decline in short-rate expectations occurred between the surveys dated July 11, 2011, and August 8, 2011, that is, in response to the first announcement that also included a lowering of the target range for the three-month CHF LIBOR. The September and October 2011 surveys show more muted responses.

To summarize, we find the dramatic declines in short-term money market rates around the SNB announcements to be exaggerated and reflect expectations about crisis measures rather than revisions to medium- and long-term expectations about future monetary policy. 


\section{Appendix B: Analytical Formulas for Policy Expectations and Term Premiums in the Preferred AFNS Model}

In this appendix, we derive the analytical formulas for policy expectations and term premiums within the preferred AFNS model of Swiss Confederation yields.

For a start, we note that the term premium is defined as

$$
T P_{t}(\tau)=y_{t}(\tau)-\frac{1}{\tau} \int_{t}^{t+\tau} E_{t}^{P}\left[r_{s}\right] d s
$$

In the preferred AFNS model, as in any AFNS model, the instantaneous short rate is defined as

$$
r_{t}=L_{t}+S_{t}
$$

while the specification of the $P$-dynamics is given by

$$
\left(\begin{array}{c}
d L_{t} \\
d S_{t} \\
d C_{t}
\end{array}\right)=\left(\begin{array}{ccc}
\kappa_{11}^{P} & 0 & 0 \\
0 & \kappa_{22}^{P} & 0 \\
\kappa_{31}^{P} & 0 & \kappa_{33}^{P}
\end{array}\right)\left[\left(\begin{array}{c}
\theta_{1}^{P} \\
\theta_{2}^{P} \\
\theta_{3}^{P}
\end{array}\right)-\left(\begin{array}{c}
L_{t} \\
S_{t} \\
C_{t}
\end{array}\right)\right] d t+\left(\begin{array}{ccc}
\sigma_{11} & 0 & 0 \\
0 & \sigma_{22} & 0 \\
0 & 0 & \sigma_{33}
\end{array}\right)\left(\begin{array}{c}
d W_{t}^{L, P} \\
d W_{t}^{S, P} \\
d W_{t}^{C, P}
\end{array}\right) .
$$

Thus, the mean-reversion matrix is given by

$$
K^{P}=\left(\begin{array}{ccc}
\kappa_{11}^{P} & 0 & 0 \\
0 & \kappa_{22}^{P} & 0 \\
\kappa_{31}^{P} & 0 & \kappa_{33}^{P}
\end{array}\right)
$$

Its matrix exponential can be calculated analytically and is given by

$$
\exp \left(-K^{P} \tau\right)=\left(\begin{array}{ccc}
e^{-\kappa_{11}^{P} \tau} & 0 & 0 \\
0 & e^{-\kappa_{22}^{P} \tau} & 0 \\
-\kappa_{31}^{P} \frac{e^{-\kappa_{11}^{P} \tau}-e^{-\kappa_{33}^{P} \tau}}{\kappa_{33}^{P}-\kappa_{11}^{P}} & 0 & e^{-\kappa_{33}^{P} \tau}
\end{array}\right)
$$

Thus, the conditional mean of the state variables is

$$
\begin{aligned}
& E_{t}^{P}\left[X_{t+\tau}\right]=\theta^{P}+\left(\begin{array}{ccc}
e^{-\kappa_{11}^{P} \tau} & 0 & 0 \\
0 & e^{-\kappa_{22}^{P} \tau} & 0 \\
-\kappa_{31}^{P} \frac{e^{-\kappa_{11}^{P} \tau}-e^{-\kappa_{33}^{P} \tau}}{\kappa_{33}^{P}-\kappa_{11}^{P}} & 0 & e^{-\kappa_{33}^{P} \tau}
\end{array}\right)\left(\begin{array}{c}
L_{t}-\theta_{1}^{P} \\
S_{t}-\theta_{2}^{P} \\
C_{t}-\theta_{3}^{P}
\end{array}\right) \\
& =\left(\begin{array}{c}
\theta_{1}^{P}+e^{-\kappa_{11}^{P} \tau}\left(L_{t}-\theta_{1}^{P}\right) \\
\theta_{2}^{P}+e^{-\kappa_{22}^{P} \tau}\left(S_{t}-\theta_{2}^{P}\right) \\
\theta_{3}^{P}-\kappa_{31}^{P} \frac{e^{-\kappa_{11}^{P} \tau}-e^{-\kappa_{33}^{P} \tau}}{\kappa_{33}^{P}-\kappa_{11}^{P}}\left(L_{t}-\theta_{1}^{P}\right)+e^{-\kappa_{33}^{P} \tau}\left(C_{t}-\theta_{3}^{P}\right)
\end{array}\right) .
\end{aligned}
$$

In order to get back to the term premium formula, we note that the conditional expectation of the instantaneous short rate process is:

$$
\begin{aligned}
E_{t}^{P}\left[r_{s}\right] & =E_{t}^{P}\left[L_{s}+S_{s}\right] \\
& =\theta_{1}^{P}+e^{-\kappa_{11}^{P}(s-t)}\left(L_{t}-\theta_{1}^{P}\right)+\theta_{2}^{P}+e^{-\kappa_{22}^{P}(s-t)}\left(S_{t}-\theta_{2}^{P}\right) .
\end{aligned}
$$


Now, we integrate the expected short rate over the time interval from $t$ to $t+\tau$ as in the definition of the term premium:

$$
\begin{aligned}
\int_{t}^{t+\tau} E_{t}^{P}\left[r_{s}\right] d s & =\int_{t}^{t+\tau}\left(\theta_{1}^{P}+e^{-\kappa_{11}^{P}(s-t)}\left(L_{t}-\theta_{1}^{P}\right)+\theta_{2}^{P}+e^{-\kappa_{22}^{P}(s-t)}\left(S_{t}-\theta_{2}^{P}\right)\right) d s \\
& =\left(\theta_{1}^{P}+\theta_{2}^{P}\right) \tau+\left(L_{t}-\theta_{1}^{P}\right) \int_{t}^{t+\tau} e^{-\kappa_{11}^{P}(s-t)} d s+\left(S_{t}-\theta_{2}^{P}\right) \int_{t}^{t+\tau} e^{-\kappa_{22}^{P}(s-t)} d s \\
& =\left(\theta_{1}^{P}+\theta_{2}^{P}\right) \tau+\left(L_{t}-\theta_{1}^{P}\right)\left[\frac{-1}{\kappa_{11}^{P}} e^{-\kappa_{11}^{P}(s-t)}\right]_{t}^{t+\tau}+\left(S_{t}-\theta_{2}^{P}\right)\left[\frac{-1}{\kappa_{22}^{P}} e^{-\kappa_{22}^{P}(s-t)}\right]_{t}^{t+\tau} \\
& =\left(\theta_{1}^{P}+\theta_{2}^{P}\right) \tau+\left(L_{t}-\theta_{1}^{P}\right) \frac{1-e^{-\kappa_{11}^{P} \tau}}{\kappa_{11}^{P}}+\left(S_{t}-\theta_{2}^{P}\right) \frac{1-e^{-\kappa_{22}^{P} \tau}}{\kappa_{22}^{P}} .
\end{aligned}
$$

The relevant term to go into the term premium formula is the average expected short rate

$$
\frac{1}{\tau} \int_{t}^{t+\tau} E_{t}^{P}\left[r_{s}\right] d s=\theta_{1}^{P}+\theta_{2}^{P}+\left(L_{t}-\theta_{1}^{P}\right) \frac{1-e^{-\kappa_{11}^{P} \tau}}{\kappa_{11}^{P} \tau}+\left(S_{t}-\theta_{2}^{P}\right) \frac{1-e^{-\kappa_{22}^{P} \tau}}{\kappa_{22}^{P} \tau} .
$$

The final expression for the term premium is then given by

$$
\begin{aligned}
T P_{t}(\tau)= & y_{t}(\tau)-\frac{1}{\tau} \int_{t}^{t+\tau} E_{t}^{P}\left[r_{s}\right] d s \\
= & L_{t}+\frac{1-e^{-\lambda \tau}}{\lambda \tau} S_{t}+\left(\frac{1-e^{-\lambda \tau}}{\lambda \tau}-e^{-\lambda \tau}\right) C_{t}-\frac{A(\tau)}{\tau} \\
& -\theta_{1}^{P}-\theta_{2}^{P}-\left(L_{t}-\theta_{1}^{P}\right) \frac{1-e^{-\kappa_{11}^{P} \tau}}{\kappa_{11}^{P} \tau}-\left(S_{t}-\theta_{2}^{P}\right) \frac{1-e^{-\kappa_{22}^{P} \tau}}{\kappa_{22}^{P} \tau} \\
= & \left(1-\frac{1-e^{-\kappa_{11}^{P} \tau}}{\kappa_{11}^{P} \tau}\right) L_{t}+\left(\frac{1-e^{-\lambda \tau}}{\lambda \tau}-\frac{1-e^{-\kappa_{22}^{P} \tau}}{\kappa_{22}^{P} \tau}\right) S_{t}+\left(\frac{1-e^{-\lambda \tau}}{\lambda \tau}-e^{-\lambda \tau}\right) C_{t} \\
& -\left(1-\frac{1-e^{-\kappa_{11}^{P} \tau}}{\kappa_{11}^{P} \tau}\right) \theta_{1}^{P}-\left(1-\frac{1-e^{-\kappa_{22}^{P} \tau}}{\kappa_{22}^{P} \tau}\right) \theta_{2}^{P}-\frac{A(\tau)}{\tau} .
\end{aligned}
$$

We now provide the formulas for the decomposition of forward rates in the preferred AFNS model.

In AFNS models, in general, the instantaneous forward rate is given by

$$
f_{t}(\tau)=L_{t}+e^{-\lambda \tau} S_{t}+\lambda \tau e^{-\lambda \tau} C_{t}+A^{f}(\tau)
$$

where the yield-adjustment term in the instantaneous forward rate function is:

$$
\begin{aligned}
A^{f}(\tau)= & -\frac{\partial A(\tau)}{\partial \tau} \\
= & -\frac{1}{2} \sigma_{11}^{2} \tau^{2}-\frac{1}{2}\left(\sigma_{21}^{2}+\sigma_{22}^{2}\right)\left(\frac{1-e^{-\lambda \tau}}{\lambda}\right)^{2} \\
& -\frac{1}{2}\left(\sigma_{31}^{2}+\sigma_{32}^{2}+\sigma_{33}^{2}\right)\left[\frac{1}{\lambda^{2}}-\frac{2}{\lambda^{2}} e^{-\lambda \tau}-\frac{2}{\lambda} \tau e^{-\lambda \tau}+\frac{1}{\lambda^{2}} e^{-2 \lambda \tau}+\frac{2}{\lambda} \tau e^{-2 \lambda \tau}+\tau^{2} e^{-2 \lambda \tau}\right] \\
& -\sigma_{11} \sigma_{21} \tau \frac{1-e^{-\lambda \tau}}{\lambda}-\sigma_{11} \sigma_{31}\left[\frac{1}{\lambda} \tau-\frac{1}{\lambda} \tau e^{-\lambda \tau}-\tau^{2} e^{-\lambda \tau}\right] \\
& -\left(\sigma_{21} \sigma_{31}+\sigma_{22} \sigma_{32}\right)\left[\frac{1}{\lambda^{2}}-\frac{2}{\lambda^{2}} e^{-\lambda \tau}-\frac{1}{\lambda} \tau e^{-\lambda \tau}+\frac{1}{\lambda^{2}} e^{-2 \lambda \tau}+\frac{1}{\lambda} \tau e^{-2 \lambda \tau}\right] .
\end{aligned}
$$

The instantaneous forward rate term premium in the preferred AFNS model is then given by

$$
\begin{aligned}
T P_{t}^{f}(\tau) & =f_{t}(\tau)-E_{t}^{P}\left[r_{t+\tau}\right] \\
& =L_{t}+e^{-\lambda \tau} S_{t}+\lambda \tau e^{-\lambda \tau} C_{t}+A^{f}(\tau)-\left(\theta_{1}^{P}+e^{-\kappa_{11}^{P} \tau}\left(L_{t}-\theta_{1}^{P}\right)+\theta_{2}^{P}+e^{-\kappa_{22}^{P} \tau}\left(S_{t}-\theta_{2}^{P}\right)\right) \\
& =\left(1-e^{-\kappa_{11}^{P} \tau}\right) L_{t}+\left(e^{-\lambda \tau}-e^{-\kappa_{22}^{P} \tau}\right) S_{t}+\lambda \tau e^{-\lambda \tau} C_{t}+A^{f}(\tau)-\left(1-e^{-\kappa_{11}^{P} \tau}\right) \theta_{1}-\left(1-e^{-\kappa_{22}^{P} \tau}\right) \theta_{2}
\end{aligned}
$$


Finally, we note that the formulas above nest the case of the independent-factor AFNS model, while policy expectations and term premiums for the unconstrained and unrestricted AFNS models have to be calculated numerically. 


\section{Appendix C: Decomposition of One-Day Yield Responses}

\begin{tabular}{llcccccc}
\hline \multirow{2}{*}{ Event } & \multicolumn{6}{c}{ Maturity } \\
\cline { 2 - 8 } & & 1-year & 2-year & 3-year & 5 -year & 7-year & 10 -year \\
\hline \multirow{3}{*}{ I } & Aug. 2, 2011 & 30 & 17 & 24 & 65 & 100 & 133 \\
& Aug. 3, 2011 & 28 & 12 & 20 & 63 & 99 & 132 \\
\cline { 2 - 8 } & Change & $\mathbf{- 2}$ & $\mathbf{- 4}$ & $\mathbf{- 4}$ & $\mathbf{- 2}$ & $\mathbf{- 1}$ & $\mathbf{- 1}$ \\
\hline \multirow{3}{*}{ II } & Aug. 9, 2011 & 26 & 13 & 14 & 47 & 83 & 119 \\
& Aug. 10, 2011 & 21 & 4 & 10 & 50 & 88 & 122 \\
\cline { 2 - 8 } & Change & $\mathbf{- 5}$ & $\mathbf{- 9}$ & $\mathbf{- 5}$ & $\mathbf{3}$ & $\mathbf{4}$ & $\mathbf{3}$ \\
\hline \multirow{3}{*}{ III } & Aug. 16, 2011 & 19 & 8 & 13 & 49 & 84 & 119 \\
\cline { 2 - 8 } & Aug. 17, 2011 & 17 & 7 & 12 & 48 & 82 & 115 \\
\hline \multirow{2}{*}{ Total net change } & $\mathbf{- 9}$ & $\mathbf{- 1 4}$ & $\mathbf{- 9}$ & $\mathbf{0}$ & $\mathbf{1}$ & $\mathbf{- 3}$ \\
\hline \multirow{2}{*}{ Change } & & $\mathbf{- 1}$ & $\mathbf{0}$ & $\mathbf{- 1}$ & $\mathbf{- 2}$ & $\mathbf{- 4}$ \\
\hline
\end{tabular}

Table 9: One-Day Responses of Swiss Government Bond Yields.

The table reports the one-day response of the six Swiss government bond yields used in model estimation around three SNB announcement dates. All numbers are measured in basis points.

\begin{tabular}{|c|c|c|c|c|c|}
\hline \multirow[b]{2}{*}{ Event } & \multirow[b]{2}{*}{ Model } & \multicolumn{3}{|c|}{ Decomposition from models } & \multirow{2}{*}{$\begin{array}{c}\text { Ten-year } \\
\text { yield }\end{array}$} \\
\hline & & $\begin{array}{l}\text { Avg. target rate } \\
\text { next ten years }\end{array}$ & $\begin{array}{c}\text { Ten-year } \\
\text { term premium }\end{array}$ & Residual & \\
\hline \multirow{4}{*}{ I Aug. 3, 2011} & Unconstrained AFNS & -4 & 2 & 0 & \multirow{4}{*}{-1} \\
\hline & Unrestricted $K^{P}$ AFNS & -2 & 0 & 1 & \\
\hline & Indep.-factor AFNS & -2 & 1 & 1 & \\
\hline & Preferred AFNS & -2 & $\mathbf{0}$ & 1 & \\
\hline \multirow{4}{*}{ II Aug. 10, 2011} & Unconstrained AFNS & -2 & 5 & 0 & \multirow{4}{*}{3} \\
\hline & Unrestricted $K^{P}$ AFNS & -2 & 5 & 0 & \\
\hline & Indep.-factor AFNS & 0 & 3 & 0 & \\
\hline & Preferred AFNS & -1 & 4 & $\mathbf{0}$ & \\
\hline \multirow{4}{*}{ III Aug. 17, 2011} & Unconstrained AFNS & 1 & -5 & -1 & \multirow{4}{*}{-4} \\
\hline & Unrestricted $K^{P}$ AFNS & 0 & -3 & -2 & \\
\hline & Indep-factor AFNS & -2 & 0 & -2 & \\
\hline & Preferred AFNS & -1 & -1 & -2 & \\
\hline \multirow{4}{*}{ Total net change } & Unconstrained AFNS & -4 & 2 & -1 & \multirow{4}{*}{-3} \\
\hline & Unrestricted $K^{P}$ AFNS & -4 & 2 & -2 & \\
\hline & Indep-factor AFNS & -4 & 3 & -2 & \\
\hline & Preferred AFNS & -4 & 2 & -2 & \\
\hline
\end{tabular}

Table 10: Decompositions of One-Day Responses of Ten-Year Yield.

The decomposition of one-day responses of the ten-year Swiss government bond yield on three SNB announcement dates into changes in (i) the average expected target rate over the next ten years, (ii) the ten-year term premium, and (iii) the unexplained residual based on empirical AFNS models of Swiss government bond yields. All changes are measured in basis points.

In this appendix, we provide the decomposition of the one-day yield responses around the SNB announcements based on our empirical models of Swiss government bond yields. Table 9 contains the one-day yield changes, while Table 10 reports the results from the model decompositions. 


\section{Appendix D: Decomposition of Five-Year Yield Responses}

In this appendix, we provide the decomposition of the one- and two-day responses of the five-year Swiss government bond yield based on our empirical models of the Swiss government bond yield curve.

\begin{tabular}{|c|c|c|c|c|c|}
\hline \multirow[b]{2}{*}{ Event } & \multirow[b]{2}{*}{ Model } & \multicolumn{3}{|c|}{ Decomposition from models } & \multirow{2}{*}{$\begin{array}{c}\text { Five-year } \\
\text { yield }\end{array}$} \\
\hline & & $\begin{array}{l}\text { Avg. target rate } \\
\text { next five years }\end{array}$ & $\begin{array}{c}\text { Five-year } \\
\text { term premium }\end{array}$ & Residual & \\
\hline \multirow{4}{*}{ I Aug. 3, 2011} & Unconstrained AFNS & -5 & 2 & 0 & \multirow{4}{*}{-2} \\
\hline & Unrestricted $K^{P}$ AFNS & -2 & 0 & 0 & \\
\hline & Indep.-factor AFNS & -3 & 1 & 0 & \\
\hline & Preferred AFNS & -2 & $\mathbf{0}$ & $\mathbf{0}$ & \\
\hline \multirow{4}{*}{ II Aug. 10, 2011} & Unconstrained AFNS & -2 & 5 & 0 & \multirow{4}{*}{3} \\
\hline & Unrestricted $K^{P}$ AFNS & -2 & 5 & 0 & \\
\hline & Indep-factor AFNS & -1 & 4 & 0 & \\
\hline & Preferred AFNS & -1 & 4 & $\mathbf{0}$ & \\
\hline \multirow{4}{*}{ III Aug. 17, 2011} & Unconstrained AFNS & 2 & -3 & 0 & \multirow{4}{*}{-1} \\
\hline & Unrestricted $K^{P}$ AFNS & 0 & -1 & 0 & \\
\hline & Indep.-factor AFNS & -2 & 1 & 0 & \\
\hline & Preferred AFNS & -2 & 1 & $\mathbf{0}$ & \\
\hline \multirow{4}{*}{ Total net change } & Unconstrained AFNS & -5 & 5 & 0 & \multirow{4}{*}{$\mathbf{0}$} \\
\hline & Unrestricted $K^{P}$ AFNS & -5 & 4 & 0 & \\
\hline & Indep-factor AFNS & -6 & 6 & 0 & \\
\hline & Preferred AFNS & -5 & 5 & $\mathbf{0}$ & \\
\hline
\end{tabular}

Table 11: Decompositions of One-Day Responses of Five-Year Yield.

The decomposition of one-day responses of the five-year Swiss government bond yield on three SNB announcement dates into changes in (i) the average expected target rate over the next five years, (ii) the five-year term premium, and (iii) the unexplained residual based on empirical AFNS models of Swiss government bond yields. All changes are measured in basis points.

Table 11 contains the decompositions of the one-day changes, while Table 12 reports the results from the model decompositions of the two-day changes. Furthermore, Table 14 in Appendix E summarizes the decompositions of the one-day responses of foreign five-year government bond yields around the time of the three SNB announcements. Finally, we also report the results of a regression of the Swiss five-year term premium on the announcement dummies and controls in Table 13. 


\begin{tabular}{|c|c|c|c|c|c|}
\hline \multirow[b]{2}{*}{ Event } & \multirow[b]{2}{*}{ Model } & \multicolumn{3}{|c|}{ Decomposition from models } & \multirow[b]{2}{*}{$\begin{array}{l}\text { Five-year } \\
\text { yield }\end{array}$} \\
\hline & & $\begin{array}{l}\text { Avg. target rate } \\
\text { next five years }\end{array}$ & $\begin{array}{c}\text { Five-year } \\
\text { term premium }\end{array}$ & Residual & \\
\hline \multirow{4}{*}{ I Aug. 3, 2011} & Unconstrained AFNS & -6 & 2 & 0 & \multirow{4}{*}{-4} \\
\hline & Unrestricted $K^{P}$ AFNS & -3 & -1 & 0 & \\
\hline & Indep-factor AFNS & -3 & 0 & 0 & \\
\hline & Preferred AFNS & -3 & -1 & $\mathbf{0}$ & \\
\hline \multirow{4}{*}{ II Aug. 10, 2011} & Unconstrained AFNS & -4 & 0 & 0 & \multirow{4}{*}{-4} \\
\hline & Unrestricted $K^{P}$ AFNS & 0 & -4 & 0 & \\
\hline & Indep-factor AFNS & 1 & -5 & 0 & \\
\hline & Preferred AFNS & 1 & -5 & $\mathbf{0}$ & \\
\hline \multirow{4}{*}{ III Aug. 17, 2011} & Unconstrained AFNS & -1 & -16 & 0 & \multirow{4}{*}{-17} \\
\hline & Unrestricted $K^{P}$ AFNS & 5 & -22 & 0 & \\
\hline & Indep.-factor AFNS & 0 & -17 & 0 & \\
\hline & Preferred AFNS & 1 & -18 & $\mathbf{0}$ & \\
\hline \multirow{4}{*}{ Total net change } & Unconstrained AFNS & -10 & -14 & 0 & \multirow{4}{*}{-25} \\
\hline & Unrestricted $K^{P}$ AFNS & 2 & -27 & 0 & \\
\hline & Indep-factor AFNS & -2 & -23 & 0 & \\
\hline & Preferred AFNS & -1 & -24 & $\mathbf{0}$ & \\
\hline
\end{tabular}

Table 12: Decompositions of Two-Day Responses of Five-Year Yield.

The decomposition of two-day responses of the five-year Swiss government bond yield on three SNB announcement dates into changes in (i) the average expected target rate over the next five years, (ii) the five-year term premium, and (iii) the unexplained residual based on empirical AFNS models of Swiss government bond yields. All changes are measured in basis points. 


\begin{tabular}{|c|c|c|c|c|}
\hline \multirow{2}{*}{ Explanatory variables } & \multicolumn{4}{|c|}{ First differences } \\
\hline & (1) & $(2)$ & $(3)$ & $(4)$ \\
\hline DUM 3 Aug 2011 & $\begin{array}{c}-0.9637^{* *} \\
(0.1891)\end{array}$ & $\begin{array}{c}0.3049 \\
(0.5189)\end{array}$ & $\begin{array}{c}-1.1513^{* *} \\
(0.3955)\end{array}$ & $\begin{array}{l}-0.0344 \\
(0.6399)\end{array}$ \\
\hline DUM 10 Aug 2011 & $\begin{array}{c}-9.2079^{* *} \\
(0.1891)\end{array}$ & $\begin{array}{c}-7.1739^{* *} \\
(0.5363)\end{array}$ & $\begin{array}{c}-5.9990^{* *} \\
(0.8442)\end{array}$ & $\begin{array}{c}-4.9177^{* *} \\
(0.8884)\end{array}$ \\
\hline DUM 17 Aug 2011 & $\begin{array}{c}-18.6922^{* *} \\
(0.1891)\end{array}$ & $\begin{array}{c}-17.3018^{* *} \\
(0.2735)\end{array}$ & $\begin{array}{c}-18.4495^{* *} \\
(0.7146)\end{array}$ & $\begin{array}{c}-17.4291^{* *} \\
(0.7219)\end{array}$ \\
\hline Euro-area term premium & & $\begin{array}{c}0.0574 \\
(0.0556)\end{array}$ & & $\begin{array}{c}0.0233 \\
(0.0579)\end{array}$ \\
\hline US term premium & & $\begin{array}{l}0.2100^{* *} \\
(0.0406)\end{array}$ & & $\begin{array}{l}0.1677^{* *} \\
(0.0426)\end{array}$ \\
\hline Bid-ask spread & & & $\begin{array}{l}-2.1900 \\
(2.0439)\end{array}$ & $\begin{array}{l}-1.8937 \\
(2.0398)\end{array}$ \\
\hline VIX & & & $\begin{array}{c}-0.4185^{* *} \\
(0.0997)\end{array}$ & $\begin{array}{c}-0.3469^{* *} \\
(0.1015)\end{array}$ \\
\hline Adjusted $R^{2}$ & 0.08 & 0.13 & 0.15 & 0.18 \\
\hline
\end{tabular}

Table 13: First Difference Regressions of the Swiss Five-Year Term Premium.

The table shows the results of regressing the daily changes in the five-year Swiss term premium from the preferred AFNS model on the matching (in time) daily changes in German and US five-year term premiums as described in the main text, in addition to the changes in the bid-ask spread in the Confederation bond market and the VIX. A constant is included in all regressions, but never significant and not shown. The sample is daily from January 4, 2010, to December 12, 2011, a total of 479 observations. Newey-West serial correlation corrected standard errors based on a lag length of five are reported in parentheses. Asterisks * and ${ }^{* *}$ indicate significance at the 5 percent and 1 percent levels, respectively. 


\section{Appendix E: Decompositions of One-Day Foreign Yield Responses}

\begin{tabular}{llcccc}
\hline \multirow{2}{*}{ Event } & \multicolumn{2}{c}{ Model } & \multicolumn{2}{c}{ Decomposition from models } & Five-year \\
\cline { 3 - 6 } & & $\begin{array}{c}\text { Avg. target rate } \\
\text { next five years }\end{array}$ & $\begin{array}{c}\text { Five-year } \\
\text { term premium }\end{array}$ & Residual & yield \\
\hline I Aug. 3, 2011 & Euro-area model & 1 & 4 & 1 & 6 \\
& US model & 5 & -4 & 0 & -7 \\
\hline \multirow{2}{*}{ II Aug. 10, 2011 } & Euro-area model & 0 & 2 & 0 & 2 \\
& US model & 2 & -4 & 3 & 1 \\
\hline \multirow{2}{*}{ III Aug. 17, 2011 } & Euro-area model & -1 & -1 & 0 & -2 \\
& US model & 1 & -3 & -1 & -3 \\
\hline \multirow{2}{*}{ Total net change } & Euro-area model & 0 & 5 & 1 & 6 \\
& US model & 8 & -11 & 2 & -1 \\
\hline
\end{tabular}

Table 14: Decompositions of One-Day Responses of Foreign Five-Year Yields.

The decomposition of one-day responses of five-year foreign government bond yields on three SNB announcement dates into changes in (i) the average expected target rate over the next five years, (ii) the five-year term premium, and (iii) the unexplained residual based on the empirical foreign term structure models described in the main text. All changes are measured in basis points.

\begin{tabular}{llcccc}
\hline \multirow{2}{*}{ Event } & \multicolumn{1}{c}{ Model } & \multicolumn{3}{c}{ Decomposition from models } & Ten-year \\
\cline { 3 - 5 } & & $\begin{array}{c}\text { Avg. target rate } \\
\text { next ten years }\end{array}$ & $\begin{array}{c}\text { Ten-year } \\
\text { term }\end{array}$ & premium & Residual \\
\hline \multirow{2}{*}{ I Aug. 3, 2011 } & Euro-area model & 1 & 4 & -4 & 1 \\
& US model & 4 & -7 & 0 & -3 \\
\hline \multirow{2}{*}{ II Aug. 10, 2011 } & Euro-area model & -1 & 3 & 1 & 3 \\
& US model & 1 & -6 & 1 & -3 \\
\hline \multirow{2}{*}{ III Aug. 17, 2011 } & Euro-area model & -1 & -1 & -1 & -3 \\
& US model & 1 & -6 & -3 & -8 \\
\hline \multirow{2}{*}{ Total net change } & Euro-area model & -1 & 6 & -4 & 1 \\
& US model & 6 & -18 & -3 & -14 \\
\hline
\end{tabular}

Table 15: Decompositions of One-Day Responses of Foreign Ten-Year Yields.

The decomposition of one-day responses of ten-year foreign government bond yields on three SNB announcement dates into changes in (i) the average expected target rate over the next ten years, (ii) the ten-year term premium, and (iii) the unexplained residual based on the empirical foreign term structure models described in the main text. All changes are measured in basis points. 


\section{Appendix F: Decompositions from Shadow-Rate Models}

In this appendix, we repeat the model-based event study analysis using the shadow-rate, arbitrage-free Nelson-Siegel (AFNS) models developed by Christensen and Rudebsuch (2015). Shadow-rate models are latent-factor models in which the state variables have standard Gaussian dynamics, but the regular short rate is replaced by a shadow short rate that may be negative, as in Black (1995). Since the short rate equals the shadow short rate truncated at zero, the model-generated short rate and yields respect the zero lower bound and have asymmetric distributions. Despite its inherent nonlinearity, shadow-rate AFNS models remain as flexible and empirically tractable as the standard AFNS models used in the main analysis. In the following, we briefly provide the details of this model class before describing the results.

In the shadow-rate AFNS model, the instantaneous risk-free rate is the nonnegative constrained process of the shadow risk-free rate with the latter being defined as the sum of level and slope as in the original AFNS model class:

$$
s_{t}=L_{t}+S_{t}, \quad r_{t}=\max \left\{0, s_{t}\right\}
$$

Also, the dynamics of the state variables used for pricing under the $Q$-measure remain as in the regular AFNS model:

$$
\left(\begin{array}{c}
d L_{t} \\
d S_{t} \\
d C_{t}
\end{array}\right)=\left(\begin{array}{ccc}
0 & 0 & 0 \\
0 & \lambda & -\lambda \\
0 & 0 & \lambda
\end{array}\right)\left[\left(\begin{array}{c}
\theta_{1}^{Q} \\
\theta_{2}^{Q} \\
\theta_{3}^{Q}
\end{array}\right)-\left(\begin{array}{c}
L_{t} \\
S_{t} \\
C_{t}
\end{array}\right)\right] d t+\Sigma\left(\begin{array}{c}
d W_{t}^{L, Q} \\
d W_{t}^{S, Q} \\
d W_{t}^{C, Q}
\end{array}\right), \quad \lambda>0 .
$$

where $\Sigma$ is the constant covariance (or volatility) matrix. ${ }^{44}$

Based on this specification of the $Q$-dynamics, the yield on the shadow discount bond that may be negative maintains the popular Nelson and Siegel (1987) factor loading structure

$$
y_{t}(\tau)=L_{t}+\left(\frac{1-e^{-\lambda \tau}}{\lambda \tau}\right) S_{t}+\left(\frac{1-e^{-\lambda \tau}}{\lambda \tau}-e^{-\lambda \tau}\right) C_{t}-\frac{A(\tau)}{\tau},
$$

where $A(\tau) / \tau$ is a maturity-dependent yield-adjustment term. The corresponding instantaneous shadow forward rate is given by

$$
f_{t}(\tau)=L_{t}+e^{-\lambda \tau} S_{t}+\lambda \tau e^{-\lambda \tau} C_{t}+A^{f}(\tau)
$$

where the final term is another maturity-dependent yield-adjustment term.

Christensen and Rudebusch (2015) show that, within the shadow-rate AFNS model, the zero-coupon bond yields that observe the zero lower bound, denoted $\underline{y}_{t}(\tau)$, are readily calculated as

$$
\underline{y}_{t}(\tau)=\frac{1}{\tau} \int_{t}^{t+\tau}\left[f_{t}(s) \Phi\left(\frac{f_{t}(s)}{\omega(s)}\right)+\omega(s) \frac{1}{\sqrt{2 \pi}} \exp \left(-\frac{1}{2}\left[\frac{f_{t}(s)}{\omega(s)}\right]^{2}\right)\right] d s,
$$

where $\Phi(\cdot)$ is the cumulative probability function for the standard normal distribution, $f_{t}(\tau)$ is the shadow

\footnotetext{
${ }^{44}$ As in the AFNS class, $\theta^{Q}$ can be set to zero without loss of generality.
} 


\begin{tabular}{|c|c|c|c|c|c|}
\hline \multirow[b]{2}{*}{ Event } & \multirow[b]{2}{*}{ Model } & \multicolumn{3}{|c|}{ Decomposition from models } & \multirow[b]{2}{*}{$\begin{array}{c}\text { Ten-year } \\
\text { yield }\end{array}$} \\
\hline & & $\begin{array}{l}\text { Avg. target rate } \\
\text { next ten years }\end{array}$ & $\begin{array}{c}\text { Ten-year } \\
\text { term premium }\end{array}$ & Residual & \\
\hline \multirow{4}{*}{ I Aug. 3, 2011} & Unconstrained B-AFNS & -10 & 7 & 1 & \multirow{4}{*}{-2} \\
\hline & Unrestricted $K^{P}$ B-AFNS & -4 & 0 & 2 & \\
\hline & Indep.-factor B-AFNS & -3 & 0 & 2 & \\
\hline & Preferred B-AFNS & -4 & $\mathbf{0}$ & 2 & \\
\hline \multirow{4}{*}{ II Aug. 10, 2011} & Unconstrained B-AFNS & -6 & 1 & 0 & \multirow{4}{*}{-6} \\
\hline & Unrestricted $K^{P}$ B-AFNS & -5 & 0 & -1 & \\
\hline & Indep.-factor B-AFNS & -3 & -1 & -1 & \\
\hline & Preferred B-AFNS & -3 & -1 & -1 & \\
\hline \multirow{4}{*}{ III Aug. 17, 2011} & Unconstrained B-AFNS & -1 & -17 & -2 & \multirow{4}{*}{-20} \\
\hline & Unrestricted $K^{P}$ B-AFNS & -7 & -12 & -1 & \\
\hline & Indep.-factor B-AFNS & -6 & -14 & -1 & \\
\hline & Preferred B-AFNS & -5 & -14 & -1 & \\
\hline \multirow{4}{*}{ Total net change } & Unconstrained B-AFNS & -18 & -10 & 0 & \multirow{4}{*}{-28} \\
\hline & Unrestricted $K^{P}$ B-AFNS & -15 & -12 & 0 & \\
\hline & Indep.-factor B-AFNS & -13 & -15 & 0 & \\
\hline & Preferred B-AFNS & -13 & -15 & $\mathbf{0}$ & \\
\hline
\end{tabular}

Table 16: Decompositions of Two-Day Responses of Ten-Year Yield.

The decomposition of two-day responses of the ten-year Swiss government bond yield on three SNB announcement dates into changes in (i) the average expected target rate over the next ten years, (ii) the ten-year term premium, and (iii) the unexplained residual based on empirical B-AFNS models of Swiss government bond yields. All changes are measured in basis points.

forward rate, and $\omega(\tau)$ takes the following simple form

$$
\begin{aligned}
\omega(\tau)^{2}= & \sigma_{11}^{2} \tau+\left(\sigma_{21}^{2}+\sigma_{22}^{2}\right) \frac{1-e^{-2 \lambda \tau}}{2 \lambda} \\
& +\left(\sigma_{31}^{2}+\sigma_{32}^{2}+\sigma_{33}^{2}\right)\left[\frac{1-e^{-2 \lambda \tau}}{4 \lambda}-\frac{1}{2} \tau e^{-2 \lambda \tau}-\frac{1}{2} \lambda \tau^{2} e^{-2 \lambda \tau}\right] \\
& +2 \sigma_{11} \sigma_{21} \frac{1-e^{-\lambda \tau}}{\lambda}+2 \sigma_{11} \sigma_{31}\left[-\tau e^{-\lambda \tau}+\frac{1-e^{-\lambda \tau}}{\lambda}\right] \\
& +\left(\sigma_{21} \sigma_{31}+\sigma_{22} \sigma_{32}\right)\left[-\tau e^{-2 \lambda \tau}+\frac{1-e^{-2 \lambda \tau}}{2 \lambda}\right]
\end{aligned}
$$

As in the affine AFNS model, the shadow-rate AFNS model is completed by specifying the price of risk using the essentially affine risk premium specification introduced by Duffee (2002). Therefore, the real-world dynamics of the state variables can be expressed as

$$
d X_{t}=K^{P}\left(\theta^{P}-X_{t}\right) d t+\Sigma d W_{t}^{P}
$$

In the unrestricted case, both $K^{P}$ and $\theta^{P}$ are allowed to vary freely relative to their counterparts under the $Q$-measure just as in the original AFNS model.

In state-space form, the model is characterized by a standard Gaussian affine transition equation (6) and a measurement equation (5), where measurement errors assumed i.i.d. with standard deviations unique to each yield maturity are added in the model estimation. Finally, we note that, due to the nonlinear measurement equation for the yields in the shadow-rate AFNS models, their estimation is based on the extended Kalman filter as described in Christensen and Rudebusch (2015). 
In the following, we refer to the shadow-rate AFNS models as "B-AFNS models." ${ }^{45}$ Table 16 contains the results of decomposing the two-day ten-year yield responses based on the empirical B-AFNS models. The results indicate a greater share of signaling effects for all three announcements. However, it remains the case that the yield response to the third and most forceful announcement is decomposed as being driven predominantly by a decline in the term premium.

\footnotetext{
${ }^{45}$ Following Kim and Singleton (2012), the prefix "B-" refers to a shadow-rate model in the spirit of Black (1995).
} 


\section{Appendix G: Important Events in August and September 2011}

Date $\quad$ Event description

Aug. 2, 2011 President Obama signs bill to raise the US federal government debt ceiling.

Aug. 3, 2011 First SNB announcement.

Aug. 4, 2011 Bank of Japan intervenes in currency markets to prop up the yen.

ECB Monetary Policy Decision: No changes to the main refinancing rate.

Aug. 6, 2011 S\&P lowers US Treasury debt rating from AAA to AA+ for the first time.

Aug. 7, 2011 ECB Statement: ECB will actively implement its securities purchase program.

Aug. 9, 2011 FOMC Statement: Federal funds target rate to remain exceptionally low at least through mid-2013.

Aug. 10, 2011 Second SNB announcement.

Aug. 11, 2011 Financial market authorities of Belgium, Italy, France, and Spain as well as the European financial regulator, ESMA, announce a ban on all forms of short selling of the shares of banks and other financial firms.

Aug. 17, 2011 Third SNB announcement.

Aug. 18, 2011 Market rumors that the ECB dollar facility was tapped for the first time since February 23, 2011. This led to a major sell-off in European bank stocks and an increase in market volatility.

Aug. 26, 2011 Federal Reserve Chairman Ben Bernanke's speech at Jackson Hole. No explicit QE news.

Sep. 6, 2011 SNB introduces exchange rate floor.

Sep. 21, 2011 FOMC statement: Announcement of the Maturity Extension Program (MEP). The program involves Treasury purchases of $\$ 400$ billion with maturities longer than 6 years, financed by sales of Treasuries with less than 3 years to maturity.

Table 17: News and Market Events in August and September 2011. 


\section{References}

Bauer, Michael D. and Glenn D. Rudebusch, 2014, "The Signaling Channel for Federal Reserve Bond Purchases," International Journal of Central Banking, Vol. 10, No. 3, 233-289.

Bernanke, Ben S. and Vincent Reinhart, 2004, "Conducting Monetary Policy at Very Low Short-Term Interest Rates," American Economic Association Papers and Proceedings, Vol. 94, No. 2, 85-90.

Black, Fisher, 1995, "Interest Rates as Options," Journal of Finance, Vol. 50, No. 7, $1371-1376$

Cahill, Michael E., Stefania D'Amico, Canlin Li, and John S. Sears, 2013, "Duration Risk versus Local Supply Channel in Treasury Yields: Evidence from the Federal Reserve's Asset Purchase Announcements," Finance and Economics Discussion Series Working Paper 2013-35, Board of Governors of the Federal Reserve System.

Carpenter, Seth, Selva Demiralp, Jane Ihrig, and Elisabeth Klee, 2013, "Analyzing Federal Reserve Asset Purchases: From whom does the Fed buy?," Finance and Economics Discussion Series Working Paper 2013-32, Board of Governors of the Federal Reserve System.

Christensen, Jens H. E., Francis X. Diebold, and Glenn D. Rudebusch, 2011, "The Affine Arbitrage-Free Class of Nelson-Siegel Term Structure Models," Journal of Econometrics, Vol. 164, No. 1, 4-20.

Christensen, Jens H. E. and James M. Gillan, 2014, "Does Quantitative Easing Affect Market Liquidity?," Working Paper 2013-26, Federal Reserve Bank of San Francisco.

Christensen, Jens H. E., Jose A. Lopez, and Glenn D. Rudebusch, 2010, "Inflation Expectations and Risk Premiums in an Arbitrage-Free Model of Nominal and Real Bond Yields," Journal of Money, Credit and Banking, Supplement to Vol. 42, No. 6, 143-178.

Christensen, Jens H. E., Jose A. Lopez, and Glenn D. Rudebusch, 2014, "Do Central Bank Liquidity Facilities Affect Interbank Lending Rates?," Journal of Business and Economic Statistics, Vol. 32, No. 1, 136-151. 
Christensen, Jens H. E., Jose A. Lopez, and Glenn D. Rudebusch, 2015, "A ProbabilityBased Stress Test of Federal Reserve Assets and Income," Journal of Monetary Economics, first published online April 8, 2015, doi:10.1016/j.jmoneco.2015.03.007.

Christensen, Jens H. E. and Glenn D. Rudebusch, 2012, "The Response of Interest Rates to U.S. and U.K. Quantitative Easing," Economic Journal, Vol. 122, No. 564, F385-F414.

Christensen, Jens H. E. and Glenn D. Rudebusch, 2013, "Modeling Yields at the Zero Lower Bound: Are Shadow Rates the Solution?," Working Paper 2013-39, Federal Reserve Bank of San Francisco.

Christensen, Jens H. E. and Glenn D. Rudebusch, 2015, "Estimating Shadow-Rate Term Structure Models with Near-Zero Yields," Journal of Financial Econometrics, Vol. 13, No. 2, 226-259.

Dai, Qiang and Kenneth J. Singleton, 2000, "Specification Analysis of Affine Term Structure Models," Journal of Finance, Vol. 55, No. 5, 1943-1978.

Diebold, Francis X. and Roberto S. Mariano, 1995, "Comparing Predictive Accuracy," Journal of Business and Economic Statistics, Vol. 13, No. 3, 253-263.

Duffee, Gregory R., 2002, "Term Premia and Interest Rate Forecasts in Affine Models," Journal of Finance, Vol. 57, No. 1, 405-443.

Ennis, Huberto M. 2014, "A Simple General Equilibrium Model of Large Excess Reserves," Working Paper Series 14-14, The Federal Reserve Bank of Richmond.

Ennis, Huberto M. and Alexander L. Wolman, 2015, "Excess Reserves in the United States: A View from the Cross-Section of Banks," International Journal of Central Banking, Vol. 11, No. 1, 251-289.

Fleming, Michael J., 2003, "Measuring Treasury Market Liquidity," Federal Reserve Bank of New York Economic Policy Review, Vol. 9, No. 3, 83-108.

Gagnon, Joseph, Matthew Raskin, Julie Remache, and Brian Sack, 2011, "The Financial Market Effects of the Federal Reserve's Large-Scale Asset Purchases," International Journal of Central Banking, Vol. 7, No. 1, 3-43.

Gertler, Mark and Peter Karadi, 2013, "QE 1 vs. 2 vs. 3. . . : A Framework for Analyzing Large-Scale Asset Purchases as a Monetary Policy Tool " International Journal of Central Banking, Vol. 9, No. 1, 5-53. 
Gürkaynak, Refet S., Brian Sack, and Jonathan H. Wright, 2007, "The U.S. Treasury Yield Curve: 1961 to the Present," Journal of Monetary Economics, Vol. 54, No. 8, 22912304.

Hamilton, James D. and Jing C. Wu, 2012, "The Effectiveness of Alternative Monetary Policy Tools in a Zero Lower Bound Environment," Journal of Money, Credit, and Banking, Supplement to Vol. 44, No. 1, 3-46.

Joyce, Michael A. S., Ana Lasaosa, Ibrahim Stevens, and Matthew Tong, 2011, "The Financial Market Impact of Quantitative Easing in the United Kingdom," International Journal of Central Banking, Vol. 7, No. 3, 113-161.

Joyce, Michael A. S. and Matthew Tong, 2012, "QE and the Gilt Market: A Disaggregated Analysis," Economic Journal, Vol. 122, No. 564, F348-F384.

Kandrac, John, 2014, "The Costs of Quantitative Easing: Liquidity and Market Functioning Effects of Federal Reserve MBS Purchases," Manuscript, Board of Governors of the Federal Reserve System.

Kettemann, Andreas and Signe Krogstrup, 2014, "Portfolio Balance Effects of the Swiss National Bank's Bond Purchase Program," Journal of Macroeconomics, Vol. 40, 132149.

Kim, Don H. and Kenneth J. Singleton, 2012, "Term Structure Models and the Zero Bound: An Empirical Investigation of Japanese Yields," Journal of Econometrics, Vol. 170, No. $1,32-49$.

Krishnamurthy, Arvind and Annette Vissing-Jorgensen, 2011, "The Effects of Quantitative Easing on Long-term Interest Rates," Brookings Papers on Economic Activity, Fall 2011, 215-265.

Krogstrup, Signe, Samuel Raynard, and Barbara Sutter, 2012, "Liquidity Effects of Quantitative Easing on Long-Term Interest Rates," SNB Working Papers 2012-2, Swiss National Bank.

Li, Canlin and Min Wei, 2013, "Term Structure Modeling with Supply Factors and the Federal Reserve's Large-Scale Asset Purchase Programs," International Journal of Central Banking, Vol. 9, No. 1, 3-39. 
Mirkov, Nikola and Barbara Sutter, 2013, "Portfolio Substitution Effect of Quantitative Easing," Manuscript. Swiss National Bank.

Neely, C.J., 2013, "The Large-Scale Asset Purchases Had Large International Effects," Working Paper 2010-018E, Federal Reserve Bank of St. Louis.

Nelson, Charles R. and Andrew F. Siegel, 1987, "Parsimonious Modeling of Yield Curves," Journal of Business, Vol. 60, No. 4, 473-489.

Ranaldo, Angelo and Enzo Rossi, 2010, "The Reaction of Asset Markets to Swiss National Bank Communication," Journal of International Money and Finance, Vol. 29, No. 3, 486-503.

Söderlind, Paul, 2010, "Reaction of Swiss Term Premia to Monetary Policy Surprises," Swiss Journal of Economics and Statistics, Vol. 146, No. 1, 385-404.

Svensson, Lars E. O., 1995, "Estimating Forward Interest Rates with the Extended Nelson \& Siegel Method," Quarterly Review, Vol. 3, Sveriges Riksbank, 13-26.

Thornton, Daniel L., 2012, "Evidence on The Portfolio Balance Channel of Quantitative Easing," Working Paper 2012-015A, Federal Reserve Bank of St. Louis.

Tobin, James, 1969, "A General Equilibrium Approach to Monetary Theory," Journal of Money, Credit and Banking, Vol. 1, No. 1, 15-29.

Vayanos, Dimitri and Jean-Luc Vila, 2009, "A Preferred-Habitat Model of the Term Structure of Interest Rates," NBER Working Paper No. 15487. 


\section{Recent SNB Working Papers}

2015-6 Jens H.E. Christensen an Signe Krogstrup: Transmission of Quantitative Easing: The Role of Central Bank Reserves

2015-5 Petra Gerlach-Kristen and Seán Lyons: Mortgage arrears in Europe: The impact of monetary and macroprudential policies.

2015-4 Reto Foellmi, Sandra Hanslin and Andreas Kohler: A dynamic North-South model of demand-induced product cycles.

2015-3 Katarina Juselius and Katrin Assenmacher: Real exchange rate persistence: The case of the Swiss franc-US dollar rate.

2015-2 Lucas Marc Fuhrer, Basil Guggenheim and Silvio Schumacher: Re-use of collateral in the repo market.

2015-1 Pinar Yeşin: Capital flow waves to and from Switzerland before and after the financial crisis.

2014-13 Thomas Nitschka: Have investors been looking for exposure to specific countries since the global financial crisis? - Insights from the Swiss franc bond market.

2014-12 Christian Grisse and Thomas Nitschka: Exchange rate returns and external adjustment: evidence from Switzerland.

2014-11 Rina Rosenblatt-Wisch and Rolf Scheufele: Quantification and characteristics of household inflation expectations in Switzerland.

2014-10 Gregor Bäurle and Daniel Kaufmann: Exchange rate and price dynamics in a small open economy - the role of the zero lower bound and monetary policy regimes.
2014-9 Matthias Gubler and Christoph Sax: Skill-Biased Technological Change and the Real Exchange Rate.

2014-8 Tommaso Mancini Griffoli, Christoph Meyer Jean-Marc Natal and Attilio Zanetti: Determinants of the Swiss Franc Real Exchange Rate.

2014-7 Konrad Adler and Christian Grisse: Real exchange rates and fundamentals: robustness across alternative model specifications.

2014-6 Matthias Gubler: Carry Trade Activities: A Multivariate Threshold Model Analysis.

2014-5 Raphael A. Auer and Aaron Mehrotra: Trade linkages and the globalisation of inflation in Asia and the Pacific.

2014-4 Cyril Monnet and Thomas Nellen: The Collateral Costs of Clearing.

2014-3 Filippo Brutti and Philip Sauré: Repatriation of Debt in the Euro Crisis: Evidence for the Secondary Market Theory.

2014-2 Simone Auer: Monetary Policy Shocks and Foreign Investment Income: Evidence from a large Bayesian VAR.

2014-1 Thomas Nitschka: The Good? The Bad? The Ugly? Which news drive (co)variation in Swiss and US bond and stock excess returns?

2013-11 Linda S. Goldberg and Christian Grisse: Time variation in asset price responses to macro announcements.
From 2015, this publication series will be renamed SNB Working Papers.

All SNB Working Papers are available for download at: www.snb.ch, Research

Subscriptions or individual issues can be ordered at: Swiss National Bank

Library

P.O. Box

$\mathrm{CH}-8022$ Zurich

Phone: +41446313284

Fax: +41446318114

E-mail: library@snb.ch 
